\title{
CEBPG transcription factor correlates with antioxidant and DNA repair genes in normal bronchial epithelial cells but not in individuals with bronchogenic carcinoma
}

\author{
D'Anna N Mullins, Erin L Crawford, Sadik A Khuder, Dawn-Alita Hernandez, \\ Youngsook Yoon and James C Willey*
}

Address: Department of Medicine, Medical University of Ohio, Room 0012 Ruppert Health Building, 3000 Arlington Avenue, Toledo, OH 43614, USA

Email: D'Anna N Mullins - damullins@meduohio.edu; Erin L Crawford - ercrawford@meduohio.edu; Sadik A Khuder -skhuder@meduohio.edu; Dawn-Alita Hernandez - dahernandez@meduohio.edu; Youngsook Yoon - yyoon@meduohio.edu; James C Willey* - jwilley@meduohio.edu

* Corresponding author

Published: 29 October 2005

BMC Cancer 2005, 5:|4| doi:10.||186/|47|-2407-5-14|
Received: 07 July 2005

Accepted: 29 October 2005

This article is available from: http://www.biomedcentral.com/I47I-2407/5//4 I

(c) 2005 Mullins et al; licensee BioMed Central Ltd.

This is an Open Access article distributed under the terms of the Creative Commons Attribution License (http://creativecommons.org/licenses/by/2.0), which permits unrestricted use, distribution, and reproduction in any medium, provided the original work is properly cited.

\begin{abstract}
Background: Cigarette smoking is the primary cause of bronchogenic carcinoma (BC), yet only 10-15\% of heavy smokers develop BC and it is likely that this variation in risk is, in part, genetically determined. We previously reported a set of antioxidant genes for which transcript abundance was lower in normal bronchial epithelial cells (NBEC) of BC individuals compared to non-BC individuals. In unpublished studies of the same NBEC samples, transcript abundance values for several DNA repair genes were correlated with these antioxidant genes. From these data, we hypothesized that antioxidant and DNA repair genes are co-regulated by one or more transcription factors and that inter-individual variation in expression and/ or function of one or more of these transcription factors is responsible for inter-individual variation in risk for BC.
\end{abstract}

Methods: The putative transcription factor recognition sites common to six of the antioxidant genes were identified through in silico DNA sequence analysis. The transcript abundance values of these transcription factors $(n=6)$ and an expanded group of antioxidant and DNA repair genes $(n=16)$ were measured simultaneously by quantitative PCR in NBEC of 24 non-BC and 25 BC individuals.

Results: CEBPG transcription factor was significantly $(p<0.01)$ correlated with eight of the antioxidant or DNA repair genes in non-BC individuals but not in $B C$ individuals. In $B C$ individuals the correlation with CEBPG was significantly $(p<0.01)$ lower than that of non-BC individuals for four of the genes $(X R C C I$, ERCC5, GSTPI, and SODI) and the difference was nearly significant for GPXI. The only other transcription factor correlated with any of these five target genes in non-BC individuals was E2FI. E2FI was correlated with GSTPI among non-BC individuals, but in contrast to CEBPG, there was no significant difference in this correlation in non-BC individuals compared to $B C$ individuals.

Conclusion: We conclude that CEBPG is the transcription factor primarily responsible for regulating transcription of key antioxidant and DNA repair genes in non-BC individuals. Further, we conclude that the heavy smokers selected for development of $B C$ are those who have sub-optimal regulation of antioxidant and DNA repair genes by CEBPG. 


\section{Background}

$\mathrm{BC}$ is currently the leading cause of cancer-related death in the United States, causing 28\% of all cancer deaths [1]. Although cigarette smoking is the primary risk factor, only $10-15 \%$ of heavy smokers (greater than 20 pack years) develop BC [1-3]. Antioxidant and DNA repair enzymes that provide protection from the effects of cigarette smoke are expressed in the progenitor cells for $\mathrm{BC}$, normal bronchial epithelial cells (NBEC) [1]. Inherited inter-individual variation in the function of these genes plays a role in determining risk for BC [4-6]. Antioxidant enzymes protect NBEC from reactive oxygen species produced by interaction with and metabolism of xenobiotics such as pollution and cigarette smoke [4-7] as well as those produced by normal cellular metabolism. Reactive oxygen species cause many damaging reactions including denaturation of proteins, cross-linking of lipids and proteins and modification of nucleic acid bases, which can lead to cancer [7]. DNA repair enzymes repair the frequent damage to DNA caused by oxidant stress as well as other stresses, including bulky adducts derived from carcinogens in cigarette smoke [8].

We previously reported that an interactive transcript abundance index comprising antioxidant genes was lower in NBEC of BC individuals compared to non-BC individuals, suggesting that $\mathrm{BC}$ individuals are selected on the basis of poor antioxidant protection [9]. In that study, there was a tendency towards correlation in transcript abundance between several pairs of antioxidant or DNA repair genes in non-BC individuals, but not in BC individuals. Gene pairs included in that observation were GSTP1/ GPX1, CAT/GPX3, and GPX3/SOD1.

Correlation is one typical characteristic of co-regulated genes. Another is shared transcription factor recognition sites in the regulatory regions of those genes [10]. Based on the above findings, it was hypothesized first, that there is inter-individual variation in regulation of key antioxidant and DNA repair genes by one or more transcription factors and second, that individuals with sub-optimal regulation are selected for development of BC if they smoke cigarettes. To test these hypotheses, transcription factor recognition sites common to the regulatory regions of the above correlated gene pairs were identified through in silico DNA sequence analysis, and their transcript abundance measured simultaneously with an expanded group of ten antioxidant and six DNA repair genes.

\section{Methods \\ NBEC sample procurement}

Brush biopsy samples of normal bronchial epithelium were obtained for research studies at the time of diagnostic bronchoscopy according to previously described methods $[9,11]$. Normal bronchial epithelium in the lung not involved with cancer was brushed prior to biopsy of the suspected cancerous area. Samples were collected in a manner satisfying all requirements of the Institutional Review Board for the Medical University of Ohio. Each BC diagnosis and subtype identification was determined by histopathological examination in the Department of Pathology at the Medical University of Ohio. NBEC samples from a total of 49 individuals, including 24 non-BC individuals and $25 \mathrm{BC}$ individuals, were evaluated in this study. The biographical characteristics of these individuals are presented in Table 1.

\section{Transcript abundance measurement}

Total RNA samples extracted from NBEC were reverse transcribed using M-MLV reverse transcriptase and oligo dT primers as previously described $[9,11]$. Standardized RT (StaRT)-PCR was used for transcript abundance measurement in these studies. With StaRT-PCR, an internal standard for each gene within a standardized mixture of internal standards (SMIS) is included in each PCR reaction. After amplification, products were electrophoresed on an Agilent 2100 Bioanalyzer using DNA Chips with DNA 1000 Kit reagents for visualization according to the manufacturer's protocol (Agilent Technologies Deutschland GmbH, Waldbronn, Germany).

The StaRT-PCR technology is licensed to Gene Express, Inc. (Toledo, OH). Many of the reagents are available commercially and were obtained through Gene Express, Inc. for this study. StaRT-PCR reagents for each of the measured genes that were not commercially available, including primers and SMIS, were prepared according to previously described methods $[11,12]$. Sequence information for the primers is provided in Table 2.

Including an internal standard within a SMIS in each measurement controls for all known sources of variation during PCR, including inhibitors in samples, and generates virtually-multiplexed transcript abundance data that are directly comparable across multiple experiments and institutions [13]. The performance characteristics of StaRT-PCR are superior to other forms of commercially available quantitative PCR technology in the areas critical to this study. With respect to these studies, the key property of a quantitative PCR method is not whether the PCR products are measured kinetically or at endpoint, but rather whether there are internal standards in each measurement or not. The overall performance characteristics of StaRT-PCR, including extensive validation of the method in independent laboratories have been presented in several recent articles and chapters [13-15]. With respect to the genes measured in this study, for each gene the StaRTPCR reagents had lower detection threshold of less than 10 molecules, linear dynamic range of more than six orders of magnitude (less than 10 to over $10^{7}$ molecules), 
Table I: Demographic data of patients from whom the NBEC samples were obtained.

\begin{tabular}{|c|c|c|c|c|c|c|}
\hline Subject \# & Group & Age & Gender & Histology & Smoking Hx' & Ethnicity \\
\hline 63 & $\mathrm{NBCl}^{2}$ & 77 & $M$ & & 75 & $W^{3}$ \\
\hline 64 & $\mathrm{NBCl}$ & 47 & $\mathrm{~F}$ & & 45 & W \\
\hline 136 & $\mathrm{NBCl}$ & 38 & $M$ & & 25 & A.A. ${ }^{4}$ \\
\hline 139 & $\mathrm{NBCl}$ & 44 & $\mathrm{~F}$ & & 17.5 & W \\
\hline 150 & $\mathrm{NBCl}$ & 70 & $\mathrm{~F}$ & & 45 & w \\
\hline 156 & $\mathrm{NBCl}$ & 46 & $\mathrm{~F}$ & & NS5 & A.A. \\
\hline 157 & $\mathrm{NBCl}$ & 60 & $M$ & & $>100$ & W \\
\hline 194 & $\mathrm{NBCl}$ & 57 & $M$ & & 3 & W \\
\hline 210 & $\mathrm{NBCl}$ & 40 & $M$ & & 34 & W \\
\hline 257 & $\mathrm{NBCl}$ & 69 & $\mathrm{~F}$ & & 20 & W \\
\hline 261 & $\mathrm{NBCl}$ & 73 & $\mathrm{~F}$ & & NS & W \\
\hline 282 & $\mathrm{NBCl}$ & 83 & $\mathrm{~F}$ & & 60 & W \\
\hline 285 & $\mathrm{NBCl}$ & 69 & $\mathrm{~F}$ & & NS & w \\
\hline 296 & $\mathrm{NBCl}$ & 43 & $F$ & & 20 & W \\
\hline 305 & $\mathrm{NBCl}$ & 50 & $\mathrm{~F}$ & & 40 & W \\
\hline 315 & $\mathrm{NBCl}$ & 64 & $M$ & & $N / A^{6}$ & W \\
\hline 330 & $\mathrm{NBCl}$ & 39 & $M$ & & NS & W \\
\hline 331 & $\mathrm{NBCl}$ & $N / A$ & $N / A$ & & $N / A$ & $N / A$ \\
\hline 334 & $\mathrm{NBCl}$ & 51 & $M$ & & $>50$ & $W$ \\
\hline 336 & $\mathrm{NBCl}$ & 31 & $\mathrm{~F}$ & & NS & $w$ \\
\hline 337 & $\mathrm{NBCl}$ & 32 & $M$ & & 22 & $N / A$ \\
\hline 339 & $\mathrm{NBCl}$ & 59 & $M$ & & 50 & $w$ \\
\hline 361 & $\mathrm{NBCl}$ & 73 & $\mathrm{~F}$ & & NS & $\mathrm{H}^{7}$ \\
\hline 363 & $\mathrm{NBCl}$ & 50 & $M$ & & 20 & A.A. \\
\hline 34 & $\mathrm{BCl}^{8}$ & 80 & $M$ & $\mathrm{NSCLC}^{9}$ & 40 & W \\
\hline 71 & $\mathrm{BCl}$ & 63 & $M$ & NSCLC & 100 & W \\
\hline 85 & $\mathrm{BCl}$ & 73 & $\mathrm{~F}$ & $S Q^{10}$ & $>100$ & W \\
\hline 88 & $\mathrm{BCl}$ & 85 & $M$ & SQ & 75 & W \\
\hline 99 & $\mathrm{BCl}$ & 63 & $M$ & NSCLC & 45 & w \\
\hline 118 & $\mathrm{BCl}$ & 72 & $M$ & SQ & 30 & w \\
\hline 146 & $\mathrm{BCl}$ & 64 & $\mathrm{~F}$ & SCLC'I & 45 & w \\
\hline 147 & $\mathrm{BCl}$ & 76 & $M$ & SCLC & 75 & w \\
\hline 158 & $\mathrm{BCl}$ & 88 & $M$ & SCLC & 115.5 & w \\
\hline 167 & $\mathrm{BCl}$ & 60 & $\mathrm{~F}$ & NSCLC & 50 & w \\
\hline 171 & $\mathrm{BCl}$ & 67 & $M$ & SCLC & 100 & w \\
\hline 191 & $\mathrm{BCl}$ & 75 & $M$ & SQ & 54 & W \\
\hline 211 & $\mathrm{BCl}$ & 71 & $M$ & SQ & 50 & w \\
\hline 212 & $\mathrm{BCl}$ & 65 & $M$ & SQ & 67.5 & w \\
\hline 247 & $\mathrm{BCl}$ & 75 & $\mathrm{~F}$ & SQ & 50 & W \\
\hline 255 & $\mathrm{BCl}$ & 60 & $\mathrm{~F}$ & NSCLC & 30 & w \\
\hline 259 & $\mathrm{BCl}$ & 68 & $M$ & $\mathrm{CS}^{12}$ & 137.5 & w \\
\hline 271 & $\mathrm{BCl}$ & 58 & $M$ & $\mathrm{AC}^{13}$ & 94.5 & w \\
\hline 287 & $\mathrm{BCl}$ & 65 & $\mathrm{~F}$ & NSCLC & 50 & W \\
\hline 300 & $\mathrm{BCl}$ & 56 & $M$ & SQ & 34 & w \\
\hline 306 & $\mathrm{BCl}$ & 46 & $M$ & SQ & 30 & w \\
\hline 314 & $\mathrm{BCl}$ & 69 & $\mathrm{~F}$ & $\mathrm{BC}^{14}$ & NS & w \\
\hline 329 & $\mathrm{BCl}$ & 76 & $\mathrm{~F}$ & $P^{15}$ & $>37.5$ & W \\
\hline 335 & $\mathrm{BCl}$ & 75 & $M$ & SCLC & 58 & A.A. \\
\hline B3 & $\mathrm{BCl}$ & 63 & $M$ & SQ & 60 & $w$ \\
\hline
\end{tabular}

IPack years; ${ }^{2}$ Non-bronchogenic carcinoma individual; ${ }^{3}$ White; ${ }^{4}$ African-American; ${ }^{5}$ Non-smoker; ${ }^{6}$ Not available; ${ }^{7}$ Hispanic; ${ }^{8}$ Bronchogenic carcinoma individual; ${ }^{9}$ Non-small cell lung cancer; ${ }^{10}$ Squamous carcinoma; 1 'Small cell lung cancer; ${ }^{2}$ Carcinoma-in-situ;

${ }^{13}$ Adenocarcinoma; ${ }^{14}$ Bronchogenic Cancer, histology not specified; ${ }^{15}$ Poorly differentiated carcinoma.

and signal-to-analyte response of $100 \%$. In addition, the presence of an internal standard controls for inter-sample variation in presence of PCR inhibitors (which often are gene-specific) and ensures no false negatives (if the PCR fails the internal standard PCR product is not observed and there are no data to report). False positives are elimi- 
Table 2: Sequence for each primer used for StaRT-PCR virtually-multiplexed transcript abundance measurement or for internal standard preparation (CT) [15].

\begin{tabular}{|c|c|c|c|c|c|}
\hline Gene & Accession \# & Primer & Sequence & Position & Product \\
\hline \multirow[t]{3}{*}{ ACTB } & X0035I & Forward & 5' ATC CTC ACC CTG AAG TAC CC 3' & 231 & \\
\hline & & Reverse & 5' CCA TCT CTT GCT CGA AGT CC 3' & 704 & $493 \mathrm{bp}$ \\
\hline & & CT & $\begin{array}{l}\text { 5' CCA TCT CTT GCT CGA AGT CCG CCA GCC AGG TCC AGA CGC A } \\
3^{\prime}\end{array}$ & 568 & 377 bp \\
\hline \multirow[t]{3}{*}{ CAT } & X04076 & Forward & 5' CCA GAA GAA AGC GGT CAA GA 3' & 1492 & \\
\hline & & Reverse & 5' AAC CTT CAT TTT CCC CTG GG 3' & 1822 & $350 \mathrm{bp}$ \\
\hline & & CT & $\begin{array}{l}\text { 5' AAC CTT CAT TTT CCC CTG GGC CAG TGA TGA GCG GGT TAC A } \\
3^{\prime}\end{array}$ & 1699 & 247 bp \\
\hline \multirow[t]{3}{*}{ CEBPB } & NM_005194 & Forward & 5' TGT CCA AAC CAA CCG CAC AT 3' & 1412 & \\
\hline & & Reverse & 5' AGC AAC AAG CCC GTA GGA AC 3' & 1657 & $265 \mathrm{bp}$ \\
\hline & & CT & $\begin{array}{l}\text { 5' AGC AAC AAG CCC GTA GGA ACA CGC GTT CAG CCA TGT TTA A } \\
3^{\prime}\end{array}$ & $157 \mid$ & 199 bp \\
\hline \multirow[t]{3}{*}{ CEBPG } & U20240 & Forward & 5' CGG TTG AAA AGC AAG CAG AAA GCA 3' & 488 & \\
\hline & & Reverse & 5' GAT CCC AGA AAA TAG CCT CCA ATG 3' & 814 & $350 \mathrm{bp}$ \\
\hline & & CT & $\begin{array}{l}\text { 5' GAT CCC AGA AAA TAG CCT CCA ATG AAC ATT CAA GCC ACA } \\
\text { AGC TC } 3^{\prime}\end{array}$ & 726 & $282 \mathrm{bp}$ \\
\hline \multirow[t]{3}{*}{ E2FI } & M96577 & Forward & 5' TGA TAC CCC AAC TCC CTC TA 3' & 2076 & \\
\hline & & Reverse & 5' AAA GCA GGA GGG AAC AGA GC 3' & 2452 & $396 \mathrm{bp}$ \\
\hline & & $\mathrm{CT}$ & 5' AAA GCA GGA GGG AAC AGA GCA CTG CAG GGA CCA CAG G 3' & 2363 & $327 \mathrm{bp}$ \\
\hline \multirow[t]{3}{*}{ E2F3 } & YI0479 & Forward & 5' TGA AAG CCC CTC CAG AAA CAA G 3' & 1019 & \\
\hline & & Reverse & 5' GCA GCA GGG GAG GCA GTA AGT T 3' & 1336 & 339 bp \\
\hline & & CT & $\begin{array}{l}\text { 5' GCA GCA GGG GAG GCA GTA AGT TGG GGA GGC CAG AGG AGA } \\
\text { AAG GT 3' }\end{array}$ & 1253 & 278 bp \\
\hline \multirow[t]{3}{*}{ E2F6 } & AF059292 & Forward & 5' GGG CCT GCT GCC ATC AAA AAT A 3' & 99 & \\
\hline & & Reverse & 5' CCG CTT TCG GAC TCC CAG TTT 3' & 283 & $205 \mathrm{bp}$ \\
\hline & & CT & $\begin{array}{l}\text { 5' CCG CTT TCG GAC TCC CAG TTA GCG ATA CAT CAA AAC GAG G } \\
3^{\prime}\end{array}$ & 184 & 125 bp \\
\hline \multirow[t]{3}{*}{$\mathrm{ERCCl}$} & MI3I94 & Forward & 5' CTG GAG CCC CGA GGA AGC 3' & 739 & \\
\hline & & Reverse & 5' CAC TGG GGG TTT CCT TTG 3' & 1049 & $328 \mathrm{bp}$ \\
\hline & & $\mathrm{CT}$ & 5' CAC TGG GGG TTT CCT TGG AAG GCC AGA TCT TCT CTT 3 & 928 & $240 \mathrm{bp}$ \\
\hline \multirow[t]{3}{*}{ ERCC2 } & $\times 52221$ & Forward & 5' GGC CTT CTT CAC CAG CTA C 3' & 1608 & \\
\hline & & Reverse & 5' GTA GTC CGT CTT GCC CCT G 3' & 2004 & $415 \mathrm{bp}$ \\
\hline & & $\mathrm{CT}$ & 5' GTA GTC CGT CTT GCC CCT GTG GAA CTG GTC CCG CAG GT 3' & 2597 & 346 bp \\
\hline \multirow[t]{3}{*}{ ERCC4 } & U643I5 & Forward & 5' AGT GCA TCT CCA TGT CCC GCT ACT A 3' & 2213 & \\
\hline & & Reverse & 5' CGA TGT TCT TAA CGT GGT GCA TCA A 3' & 2578 & $390 \mathrm{bp}$ \\
\hline & & CT & $\begin{array}{l}\text { 5' CGA TGT TCT TAA CGT GGT GCA TCA ACA GGC TGT GGC TTG } \\
\text { CTT TGT 3' }\end{array}$ & 2433 & 265 bp \\
\hline \multirow[t]{3}{*}{ ERCC5 } & DI6305 & Forward & 5' AAG GAA AGA GAA AGA AGC AGC AGC CA 3' & 3087 & \\
\hline & & Reverse & 5' CAA ACA CAG ATC TGG CGG TCA CGA GG 3' & 3501 & $440 \mathrm{bp}$ \\
\hline & & CT & $\begin{array}{l}\text { 5' CAA ACA CAG ATC TGG CGG TCA CGA GGA GCT TCC TTC ACT } \\
\text { GAG TTC TGC GAA T } 3^{\prime}\end{array}$ & 3401 & $366 \mathrm{bp}$ \\
\hline \multirow[t]{3}{*}{ EVII } & NM_00524I & Forward & 5' CGC CGG ATA TCC ACG AAG A 3' & 302 & \\
\hline & & Reverse & 5' ATG CTG AGA GCG AAT GTG C 3' & 711 & $428 \mathrm{bp}$ \\
\hline & & $\mathrm{CT}$ & 5' ATG CTG AGA GCG AAT GTG CTT AAA TGC CTT GGG ACA CT 3' & 587 & $323 \mathrm{bp}$ \\
\hline \multirow[t]{3}{*}{ GPXI } & Y00433 & Forward & 5' CCT GGT GGT GCT CGG CTT CC 3' & 522 & \\
\hline & & Reverse & 5' CAA TGG TCT GGA AGC GGC GG 3' & 852 & $350 \mathrm{bp}$ \\
\hline & & CT & $\begin{array}{l}\text { 5' CAA TGG TCT GGA AGC GGC GGA CCG GAG ACC AGG TGA TGA } \\
\text { G 3' }\end{array}$ & 757 & 279 bp \\
\hline \multirow[t]{3}{*}{ GPX3 } & DI6360 & Forward & 5' GCA GAG CCG GGG ACA AGA GAA 3' & 113 & \\
\hline & & Reverse & 5' CTG CTC TTT CTC TCC ATT GAC 3' & 471 & 379 bp \\
\hline & & $\mathrm{CT}$ & $\begin{array}{l}\text { 5' CTG CTC TTT CTC TCC ATT GAC GCT CTT CCT GTA GTG CAT } \\
\text { TCA 3' }\end{array}$ & 298 & $227 \mathrm{bp}$ \\
\hline \multirow[t]{3}{*}{ GSTMI,2,4,5 } & j03817 & Forward & 5' GGG ACG CTC CTG ATT ATG AC 3' & 122 & \\
\hline & & Reverse & 5' GCA AAC CAT GGC CGC TTC CC 3' & 442 & $340 \mathrm{bp}$ \\
\hline & & CT & $\begin{array}{l}\text { 5' GCA AAC CAT GGC CGC TTC СCT TCT CCA AAA TGT CCA CAC G } \\
3^{\prime}\end{array}$ & 301 & 219 bp \\
\hline \multirow[t]{3}{*}{ GSTM3 } & j05459 & Forward & 5' GTG CGA GTC GTC TAT GGT TC 3' & 23 & \\
\hline & & Reverse & 5' AGT TGT GTG CGG AAA TCC AT 3' & 342 & $339 \mathrm{bp}$ \\
\hline & & CT & $\begin{array}{l}\text { 5' AGT TGT GTG CGG AAA TCC ATT GCT CTG GGT GAT CTT GTT C } \\
3^{\prime}\end{array}$ & 230 & 247 bp \\
\hline GSTPI & X08058 & Forward & 5' TCC GCT GCA AAT ACA TCT CC 3' & 305 & \\
\hline
\end{tabular}


Table 2: Sequence for each primer used for StaRT-PCR virtually-multiplexed transcript abundance measurement or for internal standard preparation (CT) [15]. (Continued)

\begin{tabular}{|c|c|c|c|c|c|}
\hline & & Reverse & 5' TGT TTC CCG TTG CCA TTG AT 3' & 616 & $331 \mathrm{bp}$ \\
\hline & & CT & $\begin{array}{l}\text { 5' TGT TTC CCG TTG CCA TTG ATT AGG ACC TCA TGG ATC AGC A } \\
3^{\prime}\end{array}$ & 485 & $220 \mathrm{bp}$ \\
\hline \multirow[t]{3}{*}{ GSTTI } & X79389 & Forward & 5' GCT CTA CCT GGA CCT GCT GT 3' & 12 & \\
\hline & & Reverse & 5' GGA ACA CAG GGA ACA TCA CC 3' & 351 & $359 \mathrm{bp}$ \\
\hline & & $\mathrm{CT}$ & $\begin{array}{l}\text { 5' GGA ACA CAG GGA ACA TCA CCT AGA GCA GGA TGG CCA CAC T } \\
\text { 3' }\end{array}$ & 199 & $227 \mathrm{bp}$ \\
\hline \multirow[t]{3}{*}{ GSTZI } & U86529 & Forward & 5' TCA CCC CCT ACC CTA CCA TCA GC 3' & 806 & \\
\hline & & Reverse & 5' ATT TCA GCG CGG GCA TTC TTT 3' & 1267 & $482 \mathrm{bp}$ \\
\hline & & CT & $\begin{array}{l}\text { 5' ATT TCA GCG CGG GCA TTC TTT CCG CAT TCT CAT CTC AGC } \\
\text { CTC AC 3' }\end{array}$ & 1161 & $399 \mathrm{bp}$ \\
\hline \multirow[t]{3}{*}{ mGSTI } & J03746 & Forward & 5' GTC GGA GCA CGG ATC TAC CAC A 3' & 404 & \\
\hline & & Reverse & 5' TTC СTC TGC TCC ССТ ССТ ACC TA 3' & 623 & 242 bp \\
\hline & & CT & $\begin{array}{l}\text { 5' TTC CTC TGC TCC CCT ССT ACC TAT TTT CAG CAA CCT GTA } \\
\text { AGC C } 3^{\prime}\end{array}$ & 505 & $144 \mathrm{bp}$ \\
\hline \multirow[t]{3}{*}{ SODI } & $\times 02317$ & Forward & 5' TGA AGG TGT GGG GAA GCA TTA 3' & 153 & \\
\hline & & Reverse & 5' TTA CAC CAC AAG CCA AAC GAC 3' & 492 & $360 \mathrm{bp}$ \\
\hline & & $\mathrm{CT}$ & $\begin{array}{l}\text { 5' TTA CAC CAC AAG CCA AAC GAC TGA TGC AAT GGT CTC CTG } \\
\text { AGA 3' }\end{array}$ & 384 & $273 \mathrm{bp}$ \\
\hline \multirow[t]{3}{*}{ XPA } & DI4533 & Forward & 5' CTC GGC GAC GGC GGC TGC GGC TAC TGG AG 3' & 178 & \\
\hline & & Reverse & 5' TGT CGG ACT TCC TTT GCT TCT TCT AAT GC 3' & 629 & $480 \mathrm{bp}$ \\
\hline & & CT & $\begin{array}{l}\text { 5' TGT CGG ACT TCC TTT GCT TCT TCT AAT GCT CTT TTT TCT AAA } \\
\text { TCA CAG TCT } 3^{\prime}\end{array}$ & 487 & $360 \mathrm{bp}$ \\
\hline \multirow[t]{3}{*}{$\mathrm{XRCCl}$} & M36089 & Forward & 5' CCC CTG AAG AGA CCA AAG CA 3' & 1906 & \\
\hline & & Reverse & 5' CCA TTG AAG GCT GTG ACG TA 3' & 2241 & $355 \mathrm{bp}$ \\
\hline & & $\mathrm{CT}$ & 5' CCA TTG AAG GCT GTG ACG TAT CAG GGA CTG GCA GAT G 3' & 2142 & 276 bp \\
\hline
\end{tabular}

nated through use of a control PCR reaction with no cDNA in it.

\section{Statistical analysis}

More than 6,000 transcript abundance measurements were conducted in multiple experiments over two years to assess the six transcription factors and sixteen antioxidant and DNA repair genes in NBEC samples from 49 individuals (24 non-BC individuals and 25 BC individuals).

Correlation of each of the six transcription factors with each of the antioxidant or DNA repair genes was determined by Pearson's correlation following logarithmic transformation. The transformation was necessary due to the wide biological variation in expression of each gene among the individuals. Significance level was defined as p $<0.01$ following Bonferroni adjustment for multiple comparison, specifically comparison of each of six transcription factors to each of the antioxidant or DNA repair genes. Comparison for significant differences between pairs of correlation coefficients was done by Fisher's Ztransformation test [16].

Analysis of the relationship between virtually-multiplexed transcript abundance data for each gene with age was assessed by Pearson's correlation, with gender by t-test, and with smoking history by ANOVA followed by Duncan's test.

\section{Transcription factor recognition site analysis}

The El Dorado (Build 35) program from the Genomatix software package was used to locate the correlated genes within the genome and define 1101 base pairs of the promoter regions (1000 base pairs upstream of and 100 base pairs into the transcription start site) for each gene (Genomatix Software GmbH, Munich, Germany, [17]). The 1101 base pair sequences obtained from the El Dorado program then were used as the target sequences for putative transcription factor recognition site identification using the MatInspector Version 4.2 program, which yielded sites for 11 transcription factors (Genomatix Software $\mathrm{GmbH}$, Munich, Germany, [17]). The parameters used were the standard $(0.75)$ core similarity and the optimized matrix similarity [18]. StaRT-PCR reagents were optimized for ten of these transcription factors, including CEBPB, CEBPE, CEBPG, E2F1, E2F3, E2F4, E2F5, E2F6, EVI1, and PAX5. Four transcription factors were expressed at low and invariant levels among multiple NBEC samples and were therefore excluded from the study. The remaining six, CEBPB, CEBPG, E2F1, E2F3, E2F6, and EVI, were evaluated for correlation with an expanded group of ten antioxidant and six DNA repair genes.

\section{Results}

Virtually-multiplexed transcript abundance data were obtained for each gene in each of the 49 samples, except for E2F1 measurement in sample 147 (Table 3). A gene- 
Table 3: Virtually-multiplexed transcript abundance data.

\begin{tabular}{|c|c|c|c|c|c|c|c|c|c|c|c|c|}
\hline SUBJECT \# & GROUP & CEBPB & CEBPG & E2F I & E2F3 & E2F6 & EVII & CAT & ERCCI & ERCC2 & ERCC4 & ERCC5 \\
\hline 63 & $\mathrm{NBCl}$ & $7.2 \mathrm{E}+03$ & $6.4 \mathrm{E}+02$ & $2.7 \mathrm{E}+02$ & $1.9 \mathrm{E}+02$ & $3.4 \mathrm{E}+02$ & 6. $|E+0|$ & $2.0 \mathrm{E}+04$ & I.IE+05 & $3.8 \mathrm{E}+03$ & I.IE+02 & $4.3 \mathrm{E}+04$ \\
\hline 64 & $\mathrm{NBCl}$ & $7.9 E+03$ & $1.7 E+03$ & $2.0 \mathrm{E}+03$ & $2.0 \mathrm{E}+0 \mathrm{I}$ & $1.7 \mathrm{E}+02$ & $2.5 \mathrm{E}+0 \mathrm{I}$ & $2.5 \mathrm{E}+04$ & $3.0 \mathrm{E}+05$ & $3.4 \mathrm{E}+03$ & 8. $|E+0|$ & $2.0 \mathrm{E}+05$ \\
\hline 136 & $\mathrm{NBCl}$ & $6.2 E+03$ & 2. $I E+02$ & $7.0 \mathrm{E}+02$ & I.0E-02 & $5.0 \mathrm{E}+0 \mathrm{I}$ & $6.0 \mathrm{E}+01$ & $2.9 \mathrm{E}+03$ & $7.4 \mathrm{E}+03$ & $5.9 \mathrm{E}+02$ & $5.6 \mathrm{E}+0 \mathrm{I}$ & $1.9 E+04$ \\
\hline 139 & $\mathrm{NBCl}$ & $4.5 E+03$ & $3.4 \mathrm{E}+03$ & $2.3 \mathrm{E}+04$ & $5.6 \mathrm{E}+02$ & $1.0 \mathrm{E}+03$ & $1.0 \mathrm{E}+03$ & $6.1 E+05$ & $1.2 \mathrm{E}+06$ & $2.2 \mathrm{E}+04$ & $3.9 E+03$ & $4.6 \mathrm{E}+05$ \\
\hline 150 & $\mathrm{NBCl}$ & $8.5 E+03$ & $7.4 \mathrm{E}+02$ & $1.6 \mathrm{E}+02$ & I.IE+02 & 4. $|E+0|$ & $3.2 E+02$ & $3.5 E+04$ & $1.7 E+05$ & $5.7 \mathrm{E}+03$ & $6.9 E+02$ & $7.2 \mathrm{E}+04$ \\
\hline 156 & $\mathrm{NBCl}$ & 2. $I E+04$ & $1.2 \mathrm{E}+03$ & $7.5 \mathrm{E}+02$ & ND' & ND & $1.4 \mathrm{E}+02$ & $1.5 \mathrm{E}+04$ & $1.8 \mathrm{E}+05$ & $2.0 \mathrm{E}+03$ & $2.9 \mathrm{E}+02$ & $3.0 E+04$ \\
\hline 157 & $\mathrm{NBCl}$ & $2.3 \mathrm{E}+04$ & 4. $I E+03$ & $3.1 E+03$ & 2. $1 E+02$ & $6.1 E+02$ & $1.4 \mathrm{E}+02$ & $3.5 \mathrm{E}+05$ & $5.6 \mathrm{E}+05$ & $8.4 \mathrm{E}+03$ & $1.6 \mathrm{E}+03$ & 2. $1 E+05$ \\
\hline 194 & $\mathrm{NBCl}$ & $6.5 E+03$ & 2. $I E+03$ & $2.9 \mathrm{E}+02$ & $2.6 \mathrm{E}+02$ & $8.5 E+02$ & $4.7 E+02$ & $4.5 E+04$ & 6. $I E+05$ & $4.7 E+03$ & $4.4 \mathrm{E}+02$ & $8.9 E+04$ \\
\hline 210 & $\mathrm{NBCl}$ & $1.0 \mathrm{E}+04$ & 2. $I E+03$ & $7.6 \mathrm{E}+02$ & $4.0 \mathrm{E}+02$ & 6. $1 E+02$ & $3.6 \mathrm{E}+02$ & $7.6 \mathrm{E}+04$ & $7.6 \mathrm{E}+04$ & $3.4 \mathrm{E}+03$ & $7.7 \mathrm{E}+02$ & $7.2 E+04$ \\
\hline 257 & $\mathrm{NBCl}$ & I.IE+04 & $1.8 \mathrm{E}+03$ & $2.7 \mathrm{E}+02$ & $8.9 E+02$ & $1.7 E+03$ & $9.7 \mathrm{E}+02$ & $1.0 \mathrm{E}+05$ & $2.6 \mathrm{E}+05$ & $1.6 \mathrm{E}+03$ & $7.6 \mathrm{E}+02$ & $7.4 \mathrm{E}+04$ \\
\hline 261 & $\mathrm{NBCl}$ & $7.6 \mathrm{E}+03$ & I. $3 \mathrm{E}+03$ & $2.5 \mathrm{E}+02$ & I.7E+02 & $1.6 \mathrm{E}+02$ & $9.4 \mathrm{E}+0 \mathrm{I}$ & $4.4 \mathrm{E}+04$ & $2.7 \mathrm{E}+05$ & $5.1 E+03$ & $4.6 \mathrm{E}+02$ & $1.3 E+05$ \\
\hline 282 & $\mathrm{NBCl}$ & $6.4 \mathrm{E}+03$ & $1.2 \mathrm{E}+03$ & $5.4 \mathrm{E}+02$ & 4.IE+0I & $2.9 \mathrm{E}+0 \mathrm{I}$ & $1.2 \mathrm{E}+02$ & 4. IE+04 & $1.0 \mathrm{E}+05$ & $6.0 \mathrm{E}+03$ & $8.1 E+02$ & $4.0 \mathrm{E}+04$ \\
\hline 285 & $\mathrm{NBCl}$ & $2.6 \mathrm{E}+03$ & $4.4 \mathrm{E}+02$ & $2.5 \mathrm{E}+03$ & I.IE+03 & ND & $1.2 \mathrm{E}+02$ & $3.7 E+04$ & $9.1 E+04$ & $1.6 \mathrm{E}+03$ & $7.7 E+03$ & $1.6 \mathrm{E}+04$ \\
\hline 296 & $\mathrm{NBCl}$ & $1.9 \mathrm{E}+04$ & $1.0 \mathrm{E}+03$ & $1.0 \mathrm{E}+03$ & ND & $2.8 \mathrm{E}+0 \mathrm{I}$ & ND & $6.9 E+04$ & $2.5 \mathrm{E}+05$ & $3.6 \mathrm{E}+03$ & $1.7 E+02$ & 7.IE+04 \\
\hline 305 & $\mathrm{NBCl}$ & $1.8 \mathrm{E}+03$ & $9 .|E+0|$ & $6.1 E+02$ & ND & $8.7 E+01$ & $2.6 \mathrm{E}+02$ & $2.0 \mathrm{E}+04$ & $4.9 E+04$ & $4.3 \mathrm{E}+02$ & $2.8 \mathrm{E}+02$ & I. $3 \mathrm{E}+04$ \\
\hline 315 & $\mathrm{NBCl}$ & $3.5 \mathrm{E}+03$ & $1.3 \mathrm{E}+03$ & $1.2 \mathrm{E}+03$ & $2.0 \mathrm{E}+02$ & $7.5 \mathrm{E}+0 \mathrm{I}$ & $6.1 E+02$ & $4.7 E+04$ & 2. $I E+05$ & $2.7 E+03$ & $2.4 \mathrm{E}+03$ & $6.2 E+04$ \\
\hline 330 & $\mathrm{NBCl}$ & 2.7E+03 & $2.4 \mathrm{E}+02$ & $4.0 \mathrm{E}+02$ & I.IE+02 & $3.5 \mathrm{E}+02$ & $4.0 \mathrm{E}+02$ & $3.6 \mathrm{E}+04$ & $8.3 \mathrm{E}+04$ & $1.5 \mathrm{E}+03$ & $1.7 \mathrm{E}+03$ & $2.8 \mathrm{E}+04$ \\
\hline 331 & $\mathrm{NBCl}$ & $7.3 \mathrm{E}+03$ & $1.3 \mathrm{E}+03$ & $8.0 \mathrm{E}+02$ & ND & ND & ND & $8.6 \mathrm{E}+04$ & $2.6 \mathrm{E}+05$ & $6.5 \mathrm{E}+02$ & $6.4 \mathrm{E}+02$ & $6.2 E+04$ \\
\hline 334 & $\mathrm{NBCl}$ & $3.7 E+03$ & $6.1 E+02$ & I.IE+03 & $2.3 \mathrm{E}+0 \mathrm{I}$ & $1.9 \mathrm{E}+01$ & $4.0 \mathrm{E}+0 \mathrm{I}$ & $7.8 \mathrm{E}+04$ & $1.4 \mathrm{E}+05$ & $2.5 \mathrm{E}+03$ & $1.3 \mathrm{E}+03$ & $5.1 E+04$ \\
\hline 336 & $\mathrm{NBCl}$ & $3.6 \mathrm{E}+03$ & $8.4 \mathrm{E}+02$ & $2.8 \mathrm{E}+03$ & $4.3 \mathrm{E}+02$ & $1.2 \mathrm{E}+02$ & $2.5 \mathrm{E}+02$ & $8.9 E+04$ & 2. $I E+05$ & $7.9 E+03$ & $3.1 E+03$ & $9.5 E+04$ \\
\hline 337 & $\mathrm{NBCl}$ & $5.0 \mathrm{E}+03$ & $9.3 \mathrm{E}+02$ & I.IE+03 & $1.6 \mathrm{E}+02$ & $2.5 \mathrm{E}+02$ & ND & $6.5 E+04$ & $1.9 \mathrm{E}+05$ & $3.3 \mathrm{E}+03$ & $1.3 \mathrm{E}+03$ & $4.2 \mathrm{E}+04$ \\
\hline 339 & $\mathrm{NBCl}$ & $2.5 \mathrm{E}+03$ & $3.2 \mathrm{E}+02$ & $5.2 \mathrm{E}+02$ & $3.4 \mathrm{E}+0 \mathrm{I}$ & $4.3 \mathrm{E}+0 \mathrm{I}$ & $6.3 \mathrm{E}+01$ & $5.0 \mathrm{E}+04$ & 8.7E+04 & $2.3 \mathrm{E}+03$ & 7.7E+02 & $3.2 E+04$ \\
\hline 361 & $\mathrm{NBCl}$ & $7.9 \mathrm{E}+03$ & $2.5 \mathrm{E}+03$ & $6.7 \mathrm{E}+02$ & $5.8 \mathrm{E}+02$ & $1.4 \mathrm{E}+03$ & $3.5 \mathrm{E}+02$ & $6.7 E+04$ & $2.5 \mathrm{E}+05$ & $1.5 \mathrm{E}+03$ & $2.8 \mathrm{E}+03$ & 4.7E+04 \\
\hline 363 & $\mathrm{NBCl}$ & $6.2 \mathrm{E}+03$ & $1.7 \mathrm{E}+03$ & $1.4 \mathrm{E}+03$ & I.IE+02 & $1.9 \mathrm{E}+02$ & $5.2 \mathrm{E}+0 \mathrm{I}$ & $7.6 \mathrm{E}+04$ & $1.4 \mathrm{E}+05$ & 3.7E+03 & $7.3 \mathrm{E}+02$ & $7.2 \mathrm{E}+04$ \\
\hline 34 & $\mathrm{BCl}$ & $1.9 \mathrm{E}+03$ & $1.7 E+03$ & $5.7 \mathrm{E}+02$ & $2.4 \mathrm{E}+02$ & 1. $2 \mathrm{E}+02$ & $3.7 \mathrm{E}+02$ & $6.7 E+04$ & $5.6 \mathrm{E}+05$ & 6. $1 E+03$ & $1.5 \mathrm{E}+03$ & $1.2 \mathrm{E}+05$ \\
\hline 71 & $\mathrm{BCl}$ & $7.6 \mathrm{E}+03$ & $1.2 \mathrm{E}+03$ & $1.3 \mathrm{E}+03$ & I.7E+0I & $1.8 \mathrm{E}+02$ & $2 .|E+0|$ & $9.5 E+04$ & $6.7 E+05$ & $1.8 \mathrm{E}+04$ & $2.4 \mathrm{E}+02$ & $2.2 \mathrm{E}+05$ \\
\hline 85 & $\mathrm{BCl}$ & $1.0 \mathrm{E}+04$ & $9.7 \mathrm{E}+02$ & $8.7 \mathrm{E}+02$ & $6.3 \mathrm{E}+0 \mathrm{I}$ & ND & ND & $2.6 \mathrm{E}+04$ & $4.9 E+04$ & I.IE+03 & $3.9 \mathrm{E}+02$ & $2.3 E+04$ \\
\hline 88 & $\mathrm{BCl}$ & $1.5 \mathrm{E}+03$ & $4.0 \mathrm{E}+02$ & $4.2 \mathrm{E}+02$ & I.IE+02 & ND & ND & 3. IE+04 & $2.9 \mathrm{E}+04$ & 2.7E+03 & $3.6 \mathrm{E}+02$ & $3.9 \mathrm{E}+04$ \\
\hline 99 & $\mathrm{BCl}$ & I. $4 \mathrm{E}+04$ & $3.3 \mathrm{E}+03$ & $2.6 \mathrm{E}+03$ & $2.2 \mathrm{E}+02$ & 3. $1 E+03$ & $1.4 \mathrm{E}+02$ & 2. $I E+05$ & $2.0 \mathrm{E}+05$ & $3.7 E+03$ & $9.3 \mathrm{E}+02$ & $1.4 \mathrm{E}+05$ \\
\hline 118 & $\mathrm{BCl}$ & $1.5 \mathrm{E}+03$ & $1.2 \mathrm{E}+03$ & $2.8 \mathrm{E}+02$ & ND & ND & $1.4 \mathrm{E}+02$ & $2.4 \mathrm{E}+04$ & $3.5 \mathrm{E}+04$ & $1.9 \mathrm{E}+03$ & $1.2 \mathrm{E}+03$ & I.7E+04 \\
\hline 146 & $\mathrm{BCl}$ & $1.9 E+04$ & $1.2 \mathrm{E}+03$ & $2.3 \mathrm{E}+02$ & $1.2 \mathrm{E}+02$ & $1.6 \mathrm{E}+03$ & $6.0 \mathrm{E}+0 \mathrm{I}$ & 3.IE+04 & $1.4 \mathrm{E}+05$ & $4.9 E+03$ & $2.7 \mathrm{E}+02$ & $6.2 E+04$ \\
\hline 147 & $\mathrm{BCl}$ & $2.8 \mathrm{E}+03$ & $1.3 \mathrm{E}+03$ & $\mathrm{~N} / \mathrm{A}^{2}$ & $3.6 \mathrm{E}+02$ & $2.8 \mathrm{E}+02$ & $3.8 \mathrm{E}+02$ & 6.IE+04 & $3.0 \mathrm{E}+05$ & $2.7 E+03$ & I.IE+03 & $1.8 \mathrm{E}+04$ \\
\hline 158 & $\mathrm{BCl}$ & $4.9 E+03$ & $8.8 \mathrm{E}+02$ & $1.9 \mathrm{E}+02$ & $2.8 \mathrm{E}+0 \mathrm{I}$ & $4.0 \mathrm{E}+02$ & $6.8 \mathrm{E}+0 \mathrm{I}$ & $2.2 E+04$ & $1.4 \mathrm{E}+05$ & $1.7 E+03$ & $1.5 \mathrm{E}+02$ & $1.3 \mathrm{E}+04$ \\
\hline 167 & $\mathrm{BCl}$ & $6.7 E+03$ & $9.2 \mathrm{E}+02$ & $4.2 E+02$ & $1.8 \mathrm{E}+02$ & $8.2 E+02$ & $3.8 \mathrm{E}+02$ & $8.9 E+04$ & I.IE+05 & $2.2 E+03$ & $2.8 \mathrm{E}+02$ & 4. IE+04 \\
\hline 171 & $\mathrm{BCl}$ & $1.0 \mathrm{E}+04$ & $3.9 E+03$ & $3.2 \mathrm{E}+03$ & 5. IE +02 & $8.9 E+01$ & $2.4 \mathrm{E}+02$ & $5.3 \mathrm{E}+05$ & $8.3 E+05$ & $1.3 \mathrm{E}+04$ & $6.3 \mathrm{E}+02$ & $1.6 \mathrm{E}+05$ \\
\hline 191 & $\mathrm{BCl}$ & $1.6 \mathrm{E}+04$ & $2.4 \mathrm{E}+03$ & $1.5 \mathrm{E}+02$ & $1.5 \mathrm{E}+02$ & 7.| $|E+0|$ & $1.2 \mathrm{E}+02$ & $2.0 \mathrm{E}+04$ & $9.6 \mathrm{E}+04$ & $2.5 \mathrm{E}+03$ & $3.4 \mathrm{E}+02$ & I. $2 \mathrm{E}+04$ \\
\hline 211 & $\mathrm{BCl}$ & $3.8 \mathrm{E}+03$ & I.IE+03 & $6.5 \mathrm{E}+02$ & $6.3 \mathrm{E}+02$ & $3.2 \mathrm{E}+02$ & $2.9 \mathrm{E}+02$ & $8.3 E+04$ & $3.5 \mathrm{E}+05$ & $2.8 \mathrm{E}+03$ & $3.2 \mathrm{E}+02$ & 9. IE+04 \\
\hline 212 & $\mathrm{BCl}$ & $1.8 \mathrm{E}+04$ & $2.8 \mathrm{E}+03$ & $6.0 \mathrm{E}+02$ & $3.4 \mathrm{E}+02$ & $2.0 \mathrm{E}+02$ & $2.2 \mathrm{E}+02$ & $3.4 \mathrm{E}+04$ & 2. $1 \mathrm{E}+05$ & $5.2 \mathrm{E}+03$ & $3.0 \mathrm{E}+02$ & $3.6 \mathrm{E}+04$ \\
\hline 247 & $\mathrm{BCl}$ & $6.5 \mathrm{E}+03$ & $7.5 \mathrm{E}+02$ & $6.4 \mathrm{E}+02$ & $1.8 \mathrm{E}+02$ & ND & $1.2 \mathrm{E}+02$ & $7.8 \mathrm{E}+04$ & $4.4 \mathrm{E}+04$ & $5.5 \mathrm{E}+02$ & $2.7 \mathrm{E}+03$ & $1.3 \mathrm{E}+04$ \\
\hline 255 & $\mathrm{BCl}$ & $1.9 \mathrm{E}+04$ & $1.1 E+03$ & 6. $1 E+02$ & $1.8 \mathrm{E}+0 \mid$ & $2.3 \mathrm{E}+02$ & $7.6 \mathrm{E}+0 \mathrm{I}$ & I.IE+05 & $6.5 \mathrm{E}+05$ & $1.2 \mathrm{E}+04$ & $1.2 \mathrm{E}+03$ & $3.8 \mathrm{E}+05$ \\
\hline 259 & $\mathrm{BCl}$ & $8.4 \mathrm{E}+03$ & $6.4 \mathrm{E}+02$ & $5.1 \mathrm{IE}+02$ & ND & $6.7 \mathrm{E}+0 \mathrm{I}$ & $4.0 \mathrm{E}+0 \mathrm{I}$ & 4.7E+04 & $1.5 \mathrm{E}+05$ & $2.6 \mathrm{E}+03$ & $3.8 \mathrm{E}+02$ & $7.9 \mathrm{E}+04$ \\
\hline 271 & $\mathrm{BCl}$ & 4. $I E+03$ & $6.6 \mathrm{E}+02$ & $1.4 \mathrm{E}+03$ & $6.5 \mathrm{E}+0 \mathrm{I}$ & $2.7 E+02$ & $1.9 \mathrm{E}+02$ & $9.1 E+04$ & $1.5 \mathrm{E}+05$ & $1.6 \mathrm{E}+03$ & ND & $1.5 \mathrm{E}+05$ \\
\hline 287 & $\mathrm{BCl}$ & $8.7 E+03$ & I.IE+03 & $9.5 \mathrm{E}+01$ & $7.4 \mathrm{E}+0 \mathrm{I}$ & $4.0 \mathrm{E}+0 \mathrm{I}$ & $2.6 \mathrm{E}+02$ & 4.7E+04 & $1.2 \mathrm{E}+05$ & $6.5 E+03$ & I.IE+02 & 4. IE+04 \\
\hline 300 & $\mathrm{BCl}$ & $4.9 E+03$ & $4.4 \mathrm{E}+02$ & 4. IE+02 & $4.4 \mathrm{E}+0 \mathrm{I}$ & ND & $5 .|E+0|$ & $3.4 \mathrm{E}+04$ & $6.9 E+04$ & $1.0 \mathrm{E}+03$ & $1.0 \mathrm{E}+03$ & $2.6 \mathrm{E}+04$ \\
\hline 306 & $\mathrm{BCl}$ & $6.5 E+03$ & $6.8 \mathrm{E}+02$ & $4.9 E+02$ & $4.4 \mathrm{E}+0 \mathrm{I}$ & ND & $1.7 \mathrm{E}+0 \mathrm{I}$ & $3.7 E+04$ & $2.5 \mathrm{E}+05$ & $2.8 \mathrm{E}+03$ & $3.2 \mathrm{E}+02$ & 4.IE+04 \\
\hline 314 & $\mathrm{BCl}$ & $4.4 \mathrm{E}+03$ & $9.3 \mathrm{E}+02$ & $4.8 \mathrm{E}+02$ & $3.1 \mathrm{IE}+02$ & ND & $1.9 \mathrm{E}+02$ & $5.3 E+04$ & $6.2 \mathrm{E}+04$ & $4.5 \mathrm{E}+03$ & $5.2 \mathrm{E}+02$ & 3. $I E+04$ \\
\hline 329 & $\mathrm{BCl}$ & I. $.4 \mathrm{E}+04$ & $3.5 \mathrm{E}+02$ & $2.4 \mathrm{E}+02$ & ND & ND & ND & $7.9 E+04$ & $1.5 \mathrm{E}+05$ & $1.4 \mathrm{E}+03$ & ND & $1.5 \mathrm{E}+05$ \\
\hline 335 & $\mathrm{BCl}$ & $4.2 \mathrm{E}+03$ & $3.7 \mathrm{E}+02$ & $2.2 \mathrm{E}+03$ & $3.3 \mathrm{E}+02$ & $2.4 \mathrm{E}+02$ & $2.4 \mathrm{E}+02$ & $4.8 \mathrm{E}+04$ & $1.9 \mathrm{E}+05$ & $9.8 \mathrm{E}+03$ & 3. $I E+02$ & $3.3 E+04$ \\
\hline B3 & $\mathrm{BCl}$ & $7.4 \mathrm{E}+03$ & $9.3 \mathrm{E}+02$ & $1.4 \mathrm{E}+02$ & $2.4 \mathrm{E}+02$ & $1.8 \mathrm{E}+02$ & $3.8 \mathrm{E}+02$ & $3.4 \mathrm{E}+04$ & $1.6 \mathrm{E}+05$ & $2.2 \mathrm{E}+03$ & $2.8 \mathrm{E}+02$ & 4. IE+04 \\
\hline SUBJECT \# & GROUP & GPXI & GPX3 & GSTMI5 & GSTM3 & GSTPI & GSTTI & GSTZI & MGSTI & SODI & XPA & XRCCI \\
\hline 63 & $\mathrm{NBCl}$ & $8.4 \mathrm{E}+05$ & $1.5 \mathrm{E}+03$ & $7.3 \mathrm{E}+03$ & $3.9 E+03$ & $1.9 E+06$ & ND & $3.1 E+03$ & $1.7 E+05$ & $1.6 \mathrm{E}+05$ & $2.5 \mathrm{E}+03$ & 2. $1 \mathrm{E}+04$ \\
\hline 64 & $\mathrm{NBCl}$ & $4.4 \mathrm{E}+05$ & 3. IE+02 & $1.5 \mathrm{E}+04$ & $2.6 \mathrm{E}+03$ & $3.5 \mathrm{E}+06$ & $6.4 \mathrm{E}+03$ & $2.0 \mathrm{E}+03$ & $1.6 \mathrm{E}+05$ & $6.5 \mathrm{E}+05$ & $2.2 \mathrm{E}+03$ & $4.2 \mathrm{E}+04$ \\
\hline 136 & $\mathrm{NBCl}$ & $2.0 \mathrm{E}+05$ & $5.2 \mathrm{E}+02$ & $6.3 \mathrm{E}+03$ & $2.2 \mathrm{E}+03$ & $5.3 E+05$ & ND & $8.9 E+02$ & $3.2 E+04$ & $5.3 E+04$ & I.IE+03 & $4.4 \mathrm{E}+03$ \\
\hline 139 & $\mathrm{NBCl}$ & $1.8 \mathrm{E}+06$ & $3.2 E+03$ & $5.2 E+04$ & $8.3 E+03$ & $3.2 E+07$ & ND & $2.8 \mathrm{E}+04$ & $8.4 \mathrm{E}+05$ & $2.2 E+06$ & $2.6 \mathrm{E}+04$ & $1.6 \mathrm{E}+05$ \\
\hline 150 & $\mathrm{NBCl}$ & 2. $I E+05$ & $2.8 \mathrm{E}+03$ & I.IE+04 & I.IE+03 & $1.5 \mathrm{E}+06$ & ND & 3. $I E+03$ & $3.1 E+04$ & $2.0 \mathrm{E}+05$ & $2.0 \mathrm{E}+03$ & 3. $I E+04$ \\
\hline 156 & $\mathrm{NBCl}$ & $4.8 \mathrm{E}+05$ & $3.9 E+03$ & $1.9 \mathrm{E}+04$ & $6.5 E+03$ & $2.9 \mathrm{E}+06$ & ND & $4.9 E+03$ & $5.8 \mathrm{E}+04$ & $1.3 E+05$ & $4.0 \mathrm{E}+03$ & $2.5 E+04$ \\
\hline
\end{tabular}


Table 3: Virtually-multiplexed transcript abundance data. (Continued)

\begin{tabular}{|c|c|c|c|c|c|c|c|c|c|c|c|c|}
\hline 157 & $\mathrm{NBCl}$ & $2.4 \mathrm{E}+06$ & $2.0 \mathrm{E}+03$ & $2.6 \mathrm{E}+04$ & $3.3 \mathrm{E}+03$ & $1.8 \mathrm{E}+07$ & $8.5 E+03$ & $3.6 \mathrm{E}+03$ & $3.6 \mathrm{E}+05$ & $1.8 \mathrm{E}+06$ & $6.2 \mathrm{E}+03$ & $1.7 \mathrm{E}+05$ \\
\hline 194 & $\mathrm{NBCl}$ & $5.4 \mathrm{E}+05$ & $4.0 \mathrm{E}+03$ & I. $2 \mathrm{E}+04$ & $1.1 \mathrm{E}+03$ & $7.8 \mathrm{E}+06$ & 7.7E+03 & $3.2 \mathrm{E}+03$ & $9.6 \mathrm{E}+04$ & $5.8 \mathrm{E}+05$ & $3.7 \mathrm{E}+03$ & $2.4 \mathrm{E}+05$ \\
\hline 210 & $\mathrm{NBCl}$ & $3.2 \mathrm{E}+05$ & $3.3 \mathrm{E}+03$ & 4. IE+03 & $2.6 \mathrm{E}+03$ & $3.9 E+06$ & $1.8 \mathrm{E}+03$ & $3.7 \mathrm{E}+03$ & $7.2 \mathrm{E}+04$ & $3.3 \mathrm{E}+05$ & $4.8 \mathrm{E}+03$ & $2.9 \mathrm{E}+04$ \\
\hline 257 & $\mathrm{NBCl}$ & $6.3 \mathrm{E}+05$ & $2.5 \mathrm{E}+03$ & I.IE+04 & $1.2 \mathrm{E}+02$ & $2.8 \mathrm{E}+06$ & $8.7 E+03$ & $2.9 \mathrm{E}+03$ & $2.3 \mathrm{E}+04$ & I. $2 \mathrm{E}+05$ & $2.6 \mathrm{E}+03$ & $4.9 \mathrm{E}+04$ \\
\hline 261 & $\mathrm{NBCl}$ & $7.6 \mathrm{E}+05$ & 4.7E+03 & $1.6 \mathrm{E}+04$ & $7.4 \mathrm{E}+03$ & 3. $I E+06$ & $1.5 \mathrm{E}+03$ & $1.8 \mathrm{E}+03$ & I. $2 \mathrm{E}+05$ & $4.5 \mathrm{E}+05$ & $4.9 E+03$ & $7.2 E+04$ \\
\hline 282 & $\mathrm{NBCl}$ & $4.6 \mathrm{E}+05$ & $2.5 E+03$ & I. $3 \mathrm{E}+04$ & $2.3 \mathrm{E}+03$ & $1.9 E+06$ & I.5E+04 & $1.3 \mathrm{E}+03$ & $6.5 \mathrm{E}+04$ & $4.5 \mathrm{E}+05$ & $2.0 \mathrm{E}+03$ & 3.IE+04 \\
\hline 285 & $\mathrm{NBCl}$ & $4.3 \mathrm{E}+05$ & $5.3 \mathrm{E}+03$ & $8.4 \mathrm{E}+04$ & $6.2 \mathrm{E}+02$ & $3.5 E+06$ & $7.3 \mathrm{E}+03$ & $9.2 \mathrm{E}+03$ & $3.0 \mathrm{E}+04$ & $2.3 \mathrm{E}+05$ & ND & $2.0 \mathrm{E}+04$ \\
\hline 296 & $\mathrm{NBCl}$ & 8. IE+05 & $1.5 E+03$ & $7.4 \mathrm{E}+03$ & 4.IE+03 & $3.6 \mathrm{E}+06$ & 8. IE+03 & $4.5 \mathrm{E}+03$ & $2.0 \mathrm{E}+05$ & $5.4 \mathrm{E}+05$ & $2.6 \mathrm{E}+03$ & $5.2 E+04$ \\
\hline 305 & $\mathrm{NBCl}$ & $1.4 \mathrm{E}+05$ & $6.5 \mathrm{E}+02$ & $4.0 \mathrm{E}+03$ & $3.2 \mathrm{E}+03$ & $1.6 \mathrm{E}+06$ & ND & $6.9 \mathrm{E}+02$ & 4. $I E+04$ & $1.8 \mathrm{E}+05$ & $1.3 \mathrm{E}+03$ & $5.7 \mathrm{E}+03$ \\
\hline 315 & $\mathrm{NBCl}$ & $4.2 \mathrm{E}+05$ & $7.6 \mathrm{E}+03$ & $5.1 E+03$ & 3. IE+03 & $7.9 E+06$ & $7.2 \mathrm{E}+03$ & $4.3 \mathrm{E}+03$ & $7.3 \mathrm{E}+04$ & $4.5 \mathrm{E}+05$ & I.0E+04 & $3.8 \mathrm{E}+04$ \\
\hline 330 & $\mathrm{NBCl}$ & $1.2 \mathrm{E}+05$ & $2.0 \mathrm{E}+03$ & $5.8 \mathrm{E}+03$ & $3.5 \mathrm{E}+03$ & I.IE+06 & $3 . \mid \mathrm{E}+0 \mathrm{I}$ & $1.3 \mathrm{E}+03$ & $2.9 \mathrm{E}+04$ & $2.3 \mathrm{E}+05$ & $1.4 \mathrm{E}+03$ & I.7E+04 \\
\hline 331 & $\mathrm{NBCl}$ & 6. IE+05 & $3.4 \mathrm{E}+03$ & I. $3 \mathrm{E}+04$ & $3.6 \mathrm{E}+03$ & $7.3 \mathrm{E}+06$ & $1.0 \mathrm{E}+04$ & $1.8 \mathrm{E}+03$ & I. $2 \mathrm{E}+05$ & I. $3 E+06$ & $1.9 \mathrm{E}+03$ & $5.7 E+04$ \\
\hline 334 & $\mathrm{NBCl}$ & $6.5 E+05$ & $4.0 \mathrm{E}+03$ & 2.7E+04 & I.7E+04 & $3.7 \mathrm{E}+06$ & $4.6 \mathrm{E}+03$ & $3.0 \mathrm{E}+03$ & $6.8 \mathrm{E}+04$ & $5.9 E+05$ & $2.9 \mathrm{E}+03$ & $2.6 \mathrm{E}+04$ \\
\hline 336 & $\mathrm{NBCl}$ & 4.7E+05 & $2.7 \mathrm{E}+03$ & $4.4 \mathrm{E}+04$ & $1.6 \mathrm{E}+03$ & $3.4 \mathrm{E}+06$ & I. $2 \mathrm{E}+04$ & $8.3 \mathrm{E}+03$ & $6.2 \mathrm{E}+04$ & $5.4 \mathrm{E}+05$ & $4.2 \mathrm{E}+03$ & $1.2 \mathrm{E}+05$ \\
\hline 337 & $\mathrm{NBCl}$ & $2.8 \mathrm{E}+05$ & $2.8 \mathrm{E}+03$ & $3.8 \mathrm{E}+03$ & $4.3 \mathrm{E}+03$ & $1.5 \mathrm{E}+06$ & $5.3 \mathrm{E}+03$ & $5.6 \mathrm{E}+03$ & $4.9 \mathrm{E}+04$ & $3.3 \mathrm{E}+05$ & I.7E+03 & $4.4 \mathrm{E}+04$ \\
\hline 339 & $\mathrm{NBCl}$ & 3. IE+05 & $1.6 \mathrm{E}+04$ & $3.0 \mathrm{E}+04$ & I.IE+03 & $3.5 E+06$ & $6.6 \mathrm{E}+03$ & $2.0 \mathrm{E}+03$ & $6.6 \mathrm{E}+04$ & $2.4 \mathrm{E}+05$ & $2.5 \mathrm{E}+03$ & $2.2 \mathrm{E}+04$ \\
\hline 361 & $\mathrm{NBCl}$ & $3.7 \mathrm{E}+05$ & $8.4 \mathrm{E}+02$ & $1.5 \mathrm{E}+04$ & $1.3 \mathrm{E}+03$ & $7.8 \mathrm{E}+06$ & $3.1 \mathrm{E}+03$ & $2.7 \mathrm{E}+03$ & $4.8 \mathrm{E}+04$ & $6.4 \mathrm{E}+05$ & $6.1 \mathrm{E}+03$ & 7.7E+04 \\
\hline 363 & $\mathrm{NBCl}$ & 6. $1 E+05$ & $2.7 \mathrm{E}+03$ & $2.2 \mathrm{E}+04$ & $2.0 \mathrm{E}+03$ & $8.1 E+06$ & $9.9 \mathrm{E}+03$ & $2.4 \mathrm{E}+03$ & $9.7 \mathrm{E}+04$ & $7.0 \mathrm{E}+05$ & $7.0 \mathrm{E}+03$ & $3.6 \mathrm{E}+04$ \\
\hline 34 & $\mathrm{BCl}$ & $8.8 \mathrm{E}+05$ & 3.IE+03 & $3.4 \mathrm{E}+03$ & 5. IE +02 & $1.8 \mathrm{E}+06$ & ND & $1.9 E+03$ & 6. IE+04 & $2.9 E+05$ & 3. IE+03 & $5.6 \mathrm{E}+04$ \\
\hline 71 & $\mathrm{BCl}$ & $8.8 \mathrm{E}+05$ & I. $3 \mathrm{E}+04$ & $3.2 \mathrm{E}+04$ & $2.2 \mathrm{E}+03$ & $6.7 \mathrm{E}+06$ & ND & $2.5 \mathrm{E}+03$ & 4. $I E+05$ & $7.5 \mathrm{E}+05$ & 3. IE+03 & $5.6 \mathrm{E}+05$ \\
\hline 85 & $\mathrm{BCl}$ & $2.3 \mathrm{E}+05$ & I.IE+03 & $2.6 \mathrm{E}+04$ & 4. IE+03 & I. $2 \mathrm{E}+06$ & $1.0 \mathrm{E}+04$ & 8. $I E+02$ & $4.8 \mathrm{E}+04$ & $1.5 \mathrm{E}+05$ & $3.5 \mathrm{E}+03$ & $1.8 \mathrm{E}+04$ \\
\hline 88 & $\mathrm{BCl}$ & I. $3 E+05$ & $1.5 \mathrm{E}+03$ & $3.5 \mathrm{E}+03$ & I.IE+03 & $6.9 E+05$ & ND & $5.6 \mathrm{E}+02$ & $2.4 \mathrm{E}+04$ & $1.9 \mathrm{E}+05$ & $2.4 \mathrm{E}+03$ & $1.6 \mathrm{E}+04$ \\
\hline 99 & $\mathrm{BCl}$ & $9.0 \mathrm{E}+05$ & 2. $I E+03$ & $1.5 \mathrm{E}+04$ & $5.5 \mathrm{E}+03$ & $9.6 E+06$ & $6.7 \mathrm{E}+03$ & $8.0 \mathrm{E}+03$ & I. $2 \mathrm{E}+05$ & $9.4 \mathrm{E}+05$ & $8.5 \mathrm{E}+03$ & 4.7E+04 \\
\hline 118 & $\mathrm{BCl}$ & $8.0 \mathrm{E}+04$ & $3.8 \mathrm{E}+03$ & I. IE+04 & $4.8 \mathrm{E}+03$ & $1.7 \mathrm{E}+06$ & $4.0 \mathrm{E}+03$ & $4.5 \mathrm{E}+02$ & $4.4 \mathrm{E}+04$ & I.7E+05 & I.IE+03 & $6.1 E+03$ \\
\hline 146 & $\mathrm{BCl}$ & 4. IE+05 & $2.9 \mathrm{E}+04$ & $4.7 \mathrm{E}+04$ & $4.7 \mathrm{E}+02$ & $2.0 \mathrm{E}+06$ & 7. $I E+03$ & $1.6 \mathrm{E}+04$ & $6.6 E+04$ & I. $7 \mathrm{E}+05$ & $3.8 \mathrm{E}+04$ & $6.5 \mathrm{E}+04$ \\
\hline 147 & $\mathrm{BCl}$ & 4.IE+05 & $2.5 \mathrm{E}+03$ & $8.2 E+03$ & $7.3 \mathrm{E}+02$ & $8.8 \mathrm{E}+05$ & I.7E+03 & $1.3 \mathrm{E}+03$ & $2.3 \mathrm{E}+04$ & $6.5 \mathrm{E}+05$ & $2.3 \mathrm{E}+02$ & $7.4 \mathrm{E}+04$ \\
\hline 158 & $\mathrm{BCl}$ & $2.6 \mathrm{E}+04$ & $2.6 \mathrm{E}+03$ & $1.4 \mathrm{E}+04$ & $4.7 \mathrm{E}+03$ & $2.3 \mathrm{E}+06$ & $2.9 \mathrm{E}+03$ & $1.2 \mathrm{E}+03$ & $2.3 \mathrm{E}+04$ & $3.7 \mathrm{E}+04$ & $1.9 E+03$ & $2.3 \mathrm{E}+04$ \\
\hline 167 & $\mathrm{BCl}$ & $1.9 \mathrm{E}+05$ & $2.5 E+03$ & $5.3 E+03$ & $1.8 \mathrm{E}+03$ & $2.4 \mathrm{E}+06$ & I. $4 \mathrm{E}+04$ & $2.3 \mathrm{E}+03$ & $9.5 E+04$ & $4.0 \mathrm{E}+05$ & $2.9 \mathrm{E}+03$ & $2.8 \mathrm{E}+04$ \\
\hline $17 \mid$ & $\mathrm{BCl}$ & $1.6 \mathrm{E}+06$ & $1.7 \mathrm{E}+03$ & $1.6 \mathrm{E}+04$ & $4.0 \mathrm{E}+03$ & $7.8 \mathrm{E}+06$ & $6.0 \mathrm{E}+03$ & $6.5 \mathrm{E}+03$ & $2.5 \mathrm{E}+05$ & $1.4 \mathrm{E}+06$ & $1.4 \mathrm{E}+04$ & $6.0 \mathrm{E}+04$ \\
\hline 191 & $\mathrm{BCl}$ & $4.5 \mathrm{E}+05$ & $1.9 \mathrm{E}+03$ & $3.5 \mathrm{E}+03$ & $2.5 \mathrm{E}+02$ & I.7E+06 & $3.6 \mathrm{E}+03$ & $5.6 \mathrm{E}+02$ & 2. $I E+04$ & $1.6 \mathrm{E}+05$ & $2.5 \mathrm{E}+03$ & 2. $I E+04$ \\
\hline 211 & $\mathrm{BCl}$ & $6.0 \mathrm{E}+05$ & I.7E+04 & I.IE+04 & $1.3 \mathrm{E}+02$ & I.0E+07 & $5.5 \mathrm{E}+03$ & 4. $I E+03$ & $2.4 \mathrm{E}+04$ & 7.IE+05 & $4.3 \mathrm{E}+03$ & $8.3 E+04$ \\
\hline 212 & $\mathrm{BCl}$ & $6.5 \mathrm{E}+04$ & $1.6 \mathrm{E}+03$ & $9.6 \mathrm{E}+03$ & I.IE+03 & $4.0 \mathrm{E}+06$ & 8. IE+03 & $9.5 \mathrm{E}+02$ & $7.5 \mathrm{E}+04$ & $9.4 \mathrm{E}+04$ & 3. IE+03 & $3.6 \mathrm{E}+04$ \\
\hline 247 & $\mathrm{BCl}$ & $2.3 \mathrm{E}+05$ & $2.0 \mathrm{E}+02$ & I.4E+04 & 2. $I E+03$ & I.3E+06 & 7.IE+03 & $1.1 E+03$ & $2.4 \mathrm{E}+04$ & I. $3 E+05$ & I. $3 \mathrm{E}+03$ & I.IE+04 \\
\hline 255 & $\mathrm{BCl}$ & $1.3 \mathrm{E}+06$ & $7.3 \mathrm{E}+03$ & I.5E+04 & $2.5 \mathrm{E}+03$ & $2.8 \mathrm{E}+06$ & $3.8 \mathrm{E}+04$ & $8.1 E+03$ & I.IE+05 & $2.8 \mathrm{E}+06$ & $2.0 \mathrm{E}+03$ & $1.0 \mathrm{E}+05$ \\
\hline 259 & $\mathrm{BCl}$ & $3.0 \mathrm{E}+06$ & $5.9 \mathrm{E}+03$ & $1.4 \mathrm{E}+04$ & $7.0 \mathrm{E}+03$ & $9.2 \mathrm{E}+06$ & $5.1 \mathrm{E}+03$ & $5.1 E+03$ & I.IE+05 & $5.0 \mathrm{E}+05$ & $4.8 \mathrm{E}+03$ & 2. $I E+04$ \\
\hline 271 & $\mathrm{BCl}$ & $7.4 \mathrm{E}+05$ & $9.5 \mathrm{E}+02$ & $3.8 \mathrm{E}+03$ & $2.6 \mathrm{E}+03$ & $2.4 \mathrm{E}+06$ & $3.7 \mathrm{E}+03$ & 3. $I E+03$ & 7.IE+04 & $6.3 E+05$ & 4. IE+03 & $3.0 \mathrm{E}+04$ \\
\hline 287 & $\mathrm{BCl}$ & $5.8 \mathrm{E}+05$ & 8.7E+03 & I.IE+04 & $2.3 E+03$ & $1.9 E+06$ & I.5E+04 & $6.3 E+02$ & $8.8 \mathrm{E}+04$ & I. $2 \mathrm{E}+05$ & 4.7E+03 & $3.3 \mathrm{E}+04$ \\
\hline 300 & $\mathrm{BCl}$ & 2.7E+05 & $1.5 \mathrm{E}+03$ & $7.7 E+03$ & $5.0 \mathrm{E}+03$ & $3.7 E+06$ & 7. $I E+03$ & $1.9 \mathrm{E}+03$ & $6.7 \mathrm{E}+04$ & $3.2 \mathrm{E}+05$ & $8.0 \mathrm{E}+02$ & $1.3 \mathrm{E}+04$ \\
\hline 306 & $\mathrm{BCl}$ & $4.2 E+05$ & $2.0 \mathrm{E}+02$ & $9.7 E+03$ & $2.3 \mathrm{E}+03$ & $2.2 \mathrm{E}+06$ & ND & $4.8 \mathrm{E}+03$ & $5.6 \mathrm{E}+04$ & I.IE+06 & $4.5 \mathrm{E}+02$ & $1.9 \mathrm{E}+04$ \\
\hline 314 & $\mathrm{BCl}$ & $1.6 \mathrm{E}+05$ & $3.7 \mathrm{E}+03$ & $1.7 \mathrm{E}+04$ & I. IE+03 & $1.2 \mathrm{E}+06$ & $1.9 \mathrm{E}+02$ & $1.5 \mathrm{E}+03$ & $2.7 \mathrm{E}+04$ & $2.7 \mathrm{E}+05$ & $2.8 \mathrm{E}+03$ & $3.4 \mathrm{E}+04$ \\
\hline 329 & $\mathrm{BCl}$ & $2.3 \mathrm{E}+05$ & $8.9 E+03$ & $1.6 \mathrm{E}+04$ & $5.3 \mathrm{E}+03$ & $7.2 \mathrm{E}+06$ & $7.8 \mathrm{E}+03$ & $1.4 \mathrm{E}+03$ & $5.7 \mathrm{E}+04$ & $8.9 E+05$ & $1.9 \mathrm{E}+03$ & $4.8 \mathrm{E}+04$ \\
\hline 335 & $\mathrm{BCl}$ & 4. IE+05 & $6.5 \mathrm{E}+03$ & 2. $I E+04$ & 7. $1 \mathrm{E}+03$ & $4.3 E+06$ & $1.8 \mathrm{E}+02$ & $7.0 \mathrm{E}+03$ & $6.9 E+04$ & $5.2 \mathrm{E}+05$ & $3.9 E+03$ & $4.4 \mathrm{E}+04$ \\
\hline B3 & $\mathrm{BCl}$ & $4.0 \mathrm{E}+05$ & $3.2 \mathrm{E}+03$ & $6.0 \mathrm{E}+03$ & $3.8 \mathrm{E}+02$ & $1.6 \mathrm{E}+06$ & $7.7 \mathrm{E}+03$ & $1.8 \mathrm{E}+03$ & $1.8 \mathrm{E}+04$ & $2.6 \mathrm{E}+05$ & $3.7 \mathrm{E}+03$ & I.7E+04 \\
\hline
\end{tabular}

Virtually-multiplexed transcript abundance data for each gene (in the form of molecules/ $/ 0^{6} \beta$-actin molecules) from all experiments were included in the same Standardized Expression Database (SED). These data are now directly comparable to previously published virtually-multiplexed transcript abundance data from this laboratory [15], or to Virtually-multiplexed transcript abundance data collected by others who use the $\mathrm{NCl}$ funded (R24 CA 95806) Standardized Expression Measurement (SEM) Center. The data presented here represent more than 6,000 Virtuallymultiplexed transcript abundance measurements conducted in multiple experiments. The sixteen antioxidant or DNA repair genes and each of the six transcription factors except for E2FI were measured in each NBEC sample from 49 individuals ( 24 non-BC individuals and 25 BC individuals). 'ND, Not detectable (When 60 molecules of Competitive Template (CT) were added to the reaction, CT was detected but native template was not.)

${ }^{2} \mathrm{NA}$, Not available. E2FI was measured in all of the samples except for one BC individual (24 non-BC individuals and 24 BC individuals).

specific inhibitor in sample 147 prevented amplification of E2F1. Neither the internal standard, nor the native cDNA PCR product was observed. The presence of genespecific PCR inhibition was observable in some other samples as reduction in peak heights in internal standard PCR products relative to that expected for the number of internal standard molecules present at the beginning of the PCR reaction. However, in each such case, the PCR amplification was efficient enough to enable quantification.

\section{Bivariate analysis}

In non-BC individuals there was significant $(\mathrm{p}<0.01)$ correlation between CEBPG and eight of the 16 antioxidant 
Table 4: Bivariate analysis of virtually-multiplexed transcript abundance data values for each antioxidant or DNA repair gene versus each transcription factor.

\begin{tabular}{|c|c|c|c|c|c|c|}
\hline \multirow[b]{2}{*}{ Antioxidant/DNA Repair Genes vs Transcription Factors } & \multicolumn{2}{|c|}{ Non-BC Individuals $n=24$} & \multicolumn{2}{|c|}{ BC Individuals $n=25$} & \multicolumn{2}{|c|}{$A L L n=49$} \\
\hline & $r$ Value & p Value & $r$ Value & p Value & $r$ Value & p Value \\
\hline CAT vs CEBPB & 0.13 & I & 0.18 & I & 0.15 & I \\
\hline CAT vs CEBPG & 0.65 & 0.004 & 0.35 & 0.48 & 0.55 & $<0.0006$ \\
\hline CAT vs E2FI* & 0.54 & 0.04 & 0.68 & 0.002 & 0.56 & $<0.0006$ \\
\hline CAT vs E2F3 & 0.48 & 0.12 & 0.18 & I & 0.37 & 0.06 \\
\hline CAT vs E2F6 & 0.26 & I & 0.3 & 0.84 & 0.25 & 0.48 \\
\hline CAT vs EVII & -0.01 & 1 & 0.21 & I & 0.08 & I \\
\hline ERCCI vs CEBPB & 0.32 & 0.78 & 0.27 & I & 0.29 & 0.24 \\
\hline ERCCI vs CEBPG & 0.77 & $<0.0006$ & 0.42 & 0.24 & 0.62 & $<0.0006$ \\
\hline ERCCI vs E2FI & 0.35 & 0.54 & 0.39 & 0.36 & 0.37 & 0.06 \\
\hline $\mathrm{ERCCl}$ vs E2F3 & 0.39 & 0.36 & 0.21 & I & 0.31 & 0.18 \\
\hline ERCCI vs E2F6 & 0.17 & 1 & 0.63 & 0.005 & 0.42 & 0.02 \\
\hline ERCCI vs EVII & -0.02 & i & 0.38 & 0.36 & 0.17 & I \\
\hline ERCC2 vs CEBPB & 0.25 & I & 0.19 & I & 0.22 & 0.84 \\
\hline ERCC2 vs CEBPG & 0.63 & 0.006 & 0.39 & 0.3 & 0.53 & $<0.0006$ \\
\hline $\mathrm{ERCC2}$ vs E2FI & 0.39 & 0.36 & 0.32 & 0.72 & 0.33 & 0.12 \\
\hline ERCC2 vs E2F3 & 0.58 & 0.02 & 0.22 & I & 0.42 & 0.02 \\
\hline ERCC2 vs E2F6 & 0.37 & 0.42 & 0.51 & 0.06 & 0.42 & 0.02 \\
\hline ERCC2 vs EVII & 0.19 & I & 0.29 & 0.96 & 0.23 & 0.66 \\
\hline ERCC4 vs CEBPB & -0.35 & 0.6 & -0.11 & I & -0.16 & I \\
\hline ERCC4 vs CEBPG & 0.24 & I & 0.37 & 0.42 & 0.25 & 0.48 \\
\hline ERCC4 vs E2FI & 0.42 & 0.24 & 0.04 & I & 0.2 & I \\
\hline ERCC4 vs E2F3 & 0.6 & 0.01 & 0.33 & 0.6 & 0.33 & 0.12 \\
\hline ERCC4 vs E2F6 & -0.04 & I & 0.04 & I & 0.07 & I \\
\hline ERCC4 vs EVII & 0.24 & I & 0.33 & 0.66 & 0.27 & 0.36 \\
\hline ERCC 5 vs CEBPB & 0.4 & 0.3 & 0.28 & I & 0.33 & 0.12 \\
\hline ERCC5 vs CEBPG & 0.79 & $<0.0006$ & 0.12 & I & 0.46 & 0.005 \\
\hline ERCC5 vs E2FI & 0.44 & 0.18 & 0.45 & 0.18 & 0.44 & 0.01 \\
\hline ERCC5 vs E2F3 & 0.39 & 0.36 & -0.11 & I & 0.13 & I \\
\hline ERCC5 vs E2F6 & $0.4 I$ & 0.3 & 0.35 & 0.54 & 0.38 & 0.04 \\
\hline ERCC5 vs EVII & 0.07 & I & -0.04 & I & 0.01 & I \\
\hline GPXI vs CEBPB & 0.49 & 0.06 & 0.24 & I & 0.32 & 0.12 \\
\hline GPXI vs CEBPG & 0.72 & $<0.0006$ & 0.19 & I & 0.4 & 0.02 \\
\hline GPXI vs E2FI & 0.48 & 0.12 & 0.38 & 0.36 & 0.43 & 0.02 \\
\hline GPXI vs E2F3 & 0.22 & I & -0.004 & I & 0.08 & I \\
\hline GPXI vs E2F6 & 0.06 & 1 & 0.36 & 0.48 & 0.28 & 0.3 \\
\hline GPXI vs EVII & -0.06 & 1 & 0.2 & I & 0.1 & I \\
\hline GPX3 vs CEBPB & -0.18 & 1 & 0.14 & 1 & 0.02 & I \\
\hline GPX3 vs CEBPG & 0.13 & 1 & 0.01 & I & 0.07 & I \\
\hline GPX3 vs E2FI & -0.03 & I & -0.17 & I & -0.12 & I \\
\hline GPX3 vs E2F3 & 0.32 & 0.78 & -0.2 & I & 0.05 & I \\
\hline GPX3 vs E2F6 & -0.26 & I & 0.44 & 0.18 & 0.19 & I \\
\hline GPX3 vs EVII & 0.06 & 1 & 0.08 & I & 0.06 & I \\
\hline GSTMI-5 vs CEBPB & -0.08 & 1 & 0.43 & 0.18 & 0.17 & I \\
\hline GSTMI-5 vs CEBPG & 0.25 & 1 & 0.02 & I & 0.16 & I \\
\hline GSTMI- 5 vs E2FI & 0.51 & 0.06 & 0.23 & i & 0.41 & 0.02 \\
\hline GSTMI-5 vs E2F3 & 0.29 & 0.96 & -0.16 & I & 0.1 & I \\
\hline GSTMI-5 vs E2F6 & -0.3 & 0.9 & 0.006 & I & -0.1 & I \\
\hline GSTMI-5 vs EVII & 0.22 & I & -0.12 & I & 0.07 & I \\
\hline GSTM3 vs CEBPB & 0.01 & 1 & 0.06 & I & 0.04 & I \\
\hline GSTM3 vs CEBPG & -0.007 & I & -0.28 & I & 0.01 & I \\
\hline GSTM3 vs E2FI & 0.29 & I & 0.35 & 0.54 & 0.34 & 0.12 \\
\hline GSTM3 vs E2F3 & -0.31 & 0.84 & -0.49 & 0.06 & -0.4 & 0.03 \\
\hline GSTM3 vs E2F6 & -0.11 & I & -0.25 & I & -0.16 & I \\
\hline GSTM3 vs EVII & -0.27 & 1 & -0.25 & I & -0.25 & 0.54 \\
\hline GSTPI vs CEBPB & 0.19 & I & 0.38 & 0.36 & 0.28 & 0.36 \\
\hline GSTPI vs CEBPG & 0.74 & $<0.0006$ & 0.18 & I & 0.51 & 0.001 \\
\hline
\end{tabular}


Table 4: Bivariate analysis of virtually-multiplexed transcript abundance data values for each antioxidant or DNA repair gene versus each transcription factor. (Continued)

\begin{tabular}{|c|c|c|c|c|c|c|}
\hline GSTPI vs E2FI & 0.6 & 0.01 & 0.46 & 0.12 & 0.56 & $<0.0006$ \\
\hline GSTPI vs E2F3 & 0.32 & 0.78 & -0.25 & I & 0.07 & I \\
\hline GSTPI vs E2F6 & 0.1 & I & 0.35 & 0.48 & 0.26 & 0.42 \\
\hline GSTPI vs EVII & 0.11 & I & 0.13 & I & 0.12 & I \\
\hline GSTTI vs CEBPB & 0.03 & I & 0.45 & 0.12 & 0.24 & 0.6 \\
\hline GSTTI vs CEBPG & 0.39 & 0.36 & 0.16 & I & 0.3 & 0.24 \\
\hline GSTTI vs E2FI & 0.07 & I & -0.15 & I & -0.05 & I \\
\hline GSTTI vs E2F3 & 0.35 & 0.54 & -0.1 & I & 0.17 & I \\
\hline GSTTI vs E2F6 & 0.05 & I & 0.21 & I & 0.11 & I \\
\hline GSTTI vs EVII & -0.26 & I & 0.22 & I & -0.04 & I \\
\hline GSTZI vs CEBPB & 0.11 & I & 0.36 & 0.42 & 0.25 & 0.54 \\
\hline GSTZI vs CEBPG & 0.51 & 0.06 & 0.08 & I & 0.28 & 0.3 \\
\hline GSTZI vs E2FI & 0.64 & 0.004 & 0.5 & 0.06 & 0.58 & $<0.0006$ \\
\hline GSTZI vs E2F3 & 0.42 & 0.24 & 0.14 & I & 0.25 & 0.54 \\
\hline GSTZI vs E2F6 & -0.05 & I & 0.48 & 0.12 & 0.32 & 0.18 \\
\hline GSTZI vs EVII & 0.02 & I & 0.27 & I & 0.16 & I \\
\hline mGST vs CEBPB & 0.31 & 0.78 & 0.35 & 0.48 & 0.32 & 0.12 \\
\hline mGST vs CEBPG & 0.56 & 0.02 & 0.25 & I & 0.42 & 0.02 \\
\hline mGST vs E2FI & 0.58 & 0.02 & 0.54 & 0.04 & 0.58 & $<0.0006$ \\
\hline mGST vs E2F3 & 0.03 & I & -0.15 & I & -0.06 & I \\
\hline mGST vs E2F6 & 0.17 & I & 0.29 & 0.96 & 0.27 & 0.36 \\
\hline mGST vs EVII & -0.16 & I & 0.07 & I & -0.04 & I \\
\hline SODI vs CEBPB & 0.13 & I & 0.15 & I & 0.14 & I \\
\hline SODI vs CEBPG & 0.66 & 0.002 & 0.009 & I & 0.36 & 0.06 \\
\hline SODI vs E2FI & 0.59 & 0.02 & 0.55 & 0.04 & 0.56 & $<0.0006$ \\
\hline SODI vs E2F3 & 0.25 & I & -0.07 & I & 0.09 & I \\
\hline SODI vs E2F6 & 0.12 & 1 & 0.14 & I & 0.14 & I \\
\hline SODI vs EVII & -0.17 & I & 0.03 & I & -0.06 & I \\
\hline XPA vs CEBPB & 0.31 & 0.84 & 0.42 & 0.24 & 0.31 & 0.18 \\
\hline XPA vs CEBPG & 0.36 & 0.54 & 0.33 & 0.66 & 0.34 & 0.12 \\
\hline XPA vs E2FI & -0.05 & I & 0.22 & I & -0.02 & I \\
\hline XPA vs E2F3 & -0.07 & I & 0.14 & I & -0.01 & I \\
\hline XPA vs E2F6 & 0.55 & 0.04 & 0.46 & 0.12 & 0.4 & 0.02 \\
\hline XPA vs EVII & 0.04 & I & 0.07 & I & 0.04 & I \\
\hline XRCCI vs CEBPB & 0.36 & 0.48 & 0.28 & I & 0.32 & 0.18 \\
\hline XRCCI vs CEBPG & 0.83 & $<0.0006$ & 0.27 & I & 0.591 & $<0.0006$ \\
\hline $\mathrm{XRCCI}$ vs E2FI & 0.32 & 0.78 & 0.37 & 0.48 & 0.35 & 0.12 \\
\hline $\mathrm{XRCCI}$ vs E2F3 & 0.47 & 0.12 & 0.22 & I & 0.35 & 0.06 \\
\hline $\mathrm{XRCCI}$ vs E2F6 & 0.26 & I & 0.54 & 0.04 & 0.41 & 0.02 \\
\hline XRCCI vs EVII & -0.009 & I & 0.12 & I & 0.06 & । \\
\hline
\end{tabular}

The correlation of logarithmically transformed virtually-multiplexed transcript abundance data (Table 3) from each of the six transcription factors with each of the sixteen antioxidant or DNA repair genes was determined. The transformation was necessary due to the wide range of expression of each gene among the samples. The correlation coefficient ( $r$ value) and level of significance ( $p$ value) for each correlation are presented. Significance $(p<0.01)$ was determined using a two-tailed test following Bonferroni adjustment for six multiple comparisons (comparison of each of six transcription factors to each of the antioxidant or DNA repair genes).

*values for E2FI obtained in all but one BC individuals.

or DNA repair genes, specifically XRCC1, ERCC5, GSTP1, SOD1, GPX1, ERCC1, CAT and ERCC2 (Table 4). In contrast, in BC individuals samples CEBPG was not correlated with any of the antioxidant or DNA repair genes. These relationships were not observed with any of the other transcription factors studied.

For XRCC1, ERCC5, GSTP1, and SOD1 the correlation with CEBPG was significantly lower in BC individuals compared to non-BC individuals and the difference was nearly significant for GPX1 (Fig. 1b). Scatter plots of the relationship between CEBPG and XRCC1 in non-BC indi- viduals or $\mathrm{BC}$ individuals (Fig. 2a,b) are representative of the other four genes. Neither CEBPG, nor XRCC1, ERCC5, GSTP1, SOD1 or GPX1 was significantly correlated with age, gender, or smoking history in non-BC individuals, $\mathrm{BC}$ individuals, or the combined group.

In non-BC individuals, based on the $r^{2}$ values from Pearson's correlation analysis, CEBPG accounts for much of the variance in expression of XRCC1 (69\%), ERCC5 (62\%), GSTP1 (55\%), SOD1 (44\%), and GPX1 (52\%). E2F1 accounts for some of the remaining variance. For example, when samples from all 49 non-BC individuals 

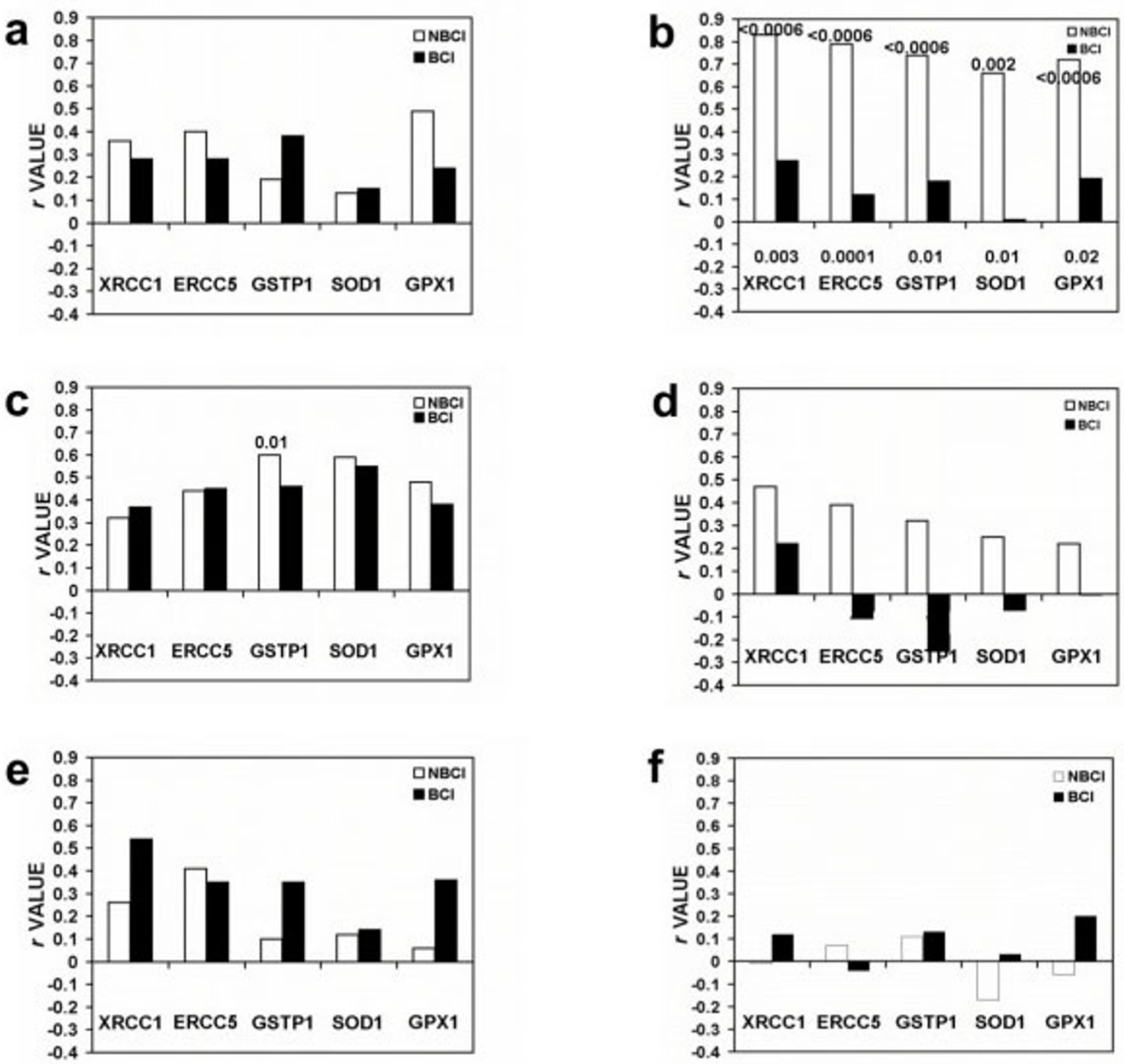

\section{Figure I}

Correlation of each transcription factor with XRCCI, ERCC5, GSTPI, SOD I, or GPXI. (a-f) Each panel presents the correlation coefficients ( $r$ values) for one transcription factor in relation to each of the five genes: (a) CEBPB, (b) CEBPG, (c) E2FI, (d) E2F3, (e) E2F6, (f) EVII. The p value for each significant correlation is provided above the bar. For CEBPG, presented in panel $\mathbf{b}$, the difference in $r$ value between non-BC individuals and BC individuals was significant or nearly significant for each correlated gene, and the $p$ value for each comparison is provided below the corresponding pair of bars.

and BC individuals were assessed as a single group, E2F1 was significantly correlated with ERCC5, GSTP1 and SOD1 (Table 4). Further, in non-BC individuals, E2F1 was correlated with GSTP1 (Fig. 1c) and the correlation was lower in $\mathrm{BC}$ individuals. However, the difference in correlation between non-BC individuals and $\mathrm{BC}$ individuals was not significant. None of the other transcription fac- tors were correlated with XRCC1, ERCC5, GSTP1, SOD1, or GPX1 (Fig. 1a,d,e,f).

\section{Comparison of gene expression with demographic characteristics}

E2F1 and GSTZ1 each were positively correlated with age. GSTM1-5 was the only gene with a difference in expres- 

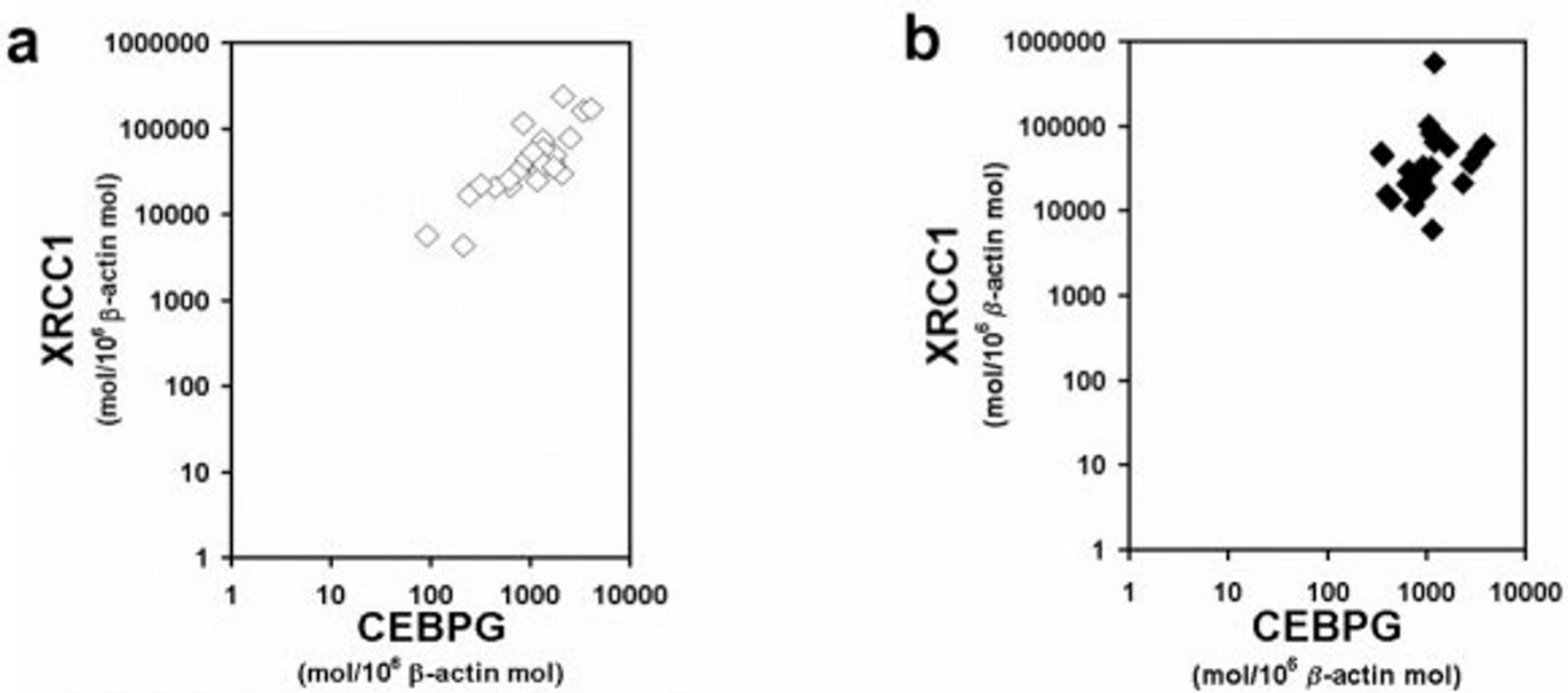

\section{Figure 2}

Scatter plot representation of bivariate correlation of CEBPG with XRCCI. (a, b) CEBPG/XRCCI data from Figure Ib presented as scatter plots: (a) non-BC individuals, (b) BC individuals.

sion by gender. There was a difference in ERCC2 expression between former and never smokers.

\section{Discussion}

In this study, we tested two hypotheses. First, that there is inter-individual variation in regulation of key antioxidant and DNA repair genes by one or more transcription factors. Second, that individuals with sub-optimal regulation are selected for development of $\mathrm{BC}$ if they smoke cigarettes.

These hypotheses are supported by the findings that a) there was large inter-individual variation in transcript levels of CEBPG and each of the target genes and in non-BC individuals, b) CEBPG transcript abundance values were significantly correlated by bivariate analysis with the transcript abundance values of four key antioxidant and DNA repair genes in non- $\mathrm{BC}$ individuals, and $\mathrm{c}$ ) that there was no correlation between CEBPG and these genes in BC individuals.

These results support the hypothesis that each of the antioxidant or DNA repair genes correlated with CEBPG in non-BC individuals is regulated by CEBPG. This is supported by the specificity of the CEBPG correlation. That is, there was lack of correlation between any of the other five transcription factors assessed and these target genes. Of particular note is the lack of correlation of the target genes with CEBPB, which binds to the same recognition site as CEBPG, and shares its recognition site within each of the antioxidant or DNA repair genes. However, there are alternative explanations for the observed correlation of CEBPG with antioxidant and DNA repair genes in non-BC individuals. One possibility is that CEBPG and each of the correlated antioxidant or DNA repair genes is regulated by a transcription factor that is as yet undiscovered, and/or has a recognition site that is not yet known and was not in the Genomatix software database.

There also is more than one possible explanation for the observed lack of correlation between CEBPG and antioxidant or DNA repair genes in BC individuals. For example, the non- $\mathrm{BC}$ individual and $\mathrm{BC}$ individual groups are not perfectly matched with respect to age, gender or smoking history (Table 1) and each of these factors could contribute to the observed difference in correlation between groups. However, the lack of association of transcript abundance level for CEBPG, XRCC1, ERCC5, GSTP1, SOD1, or GPX1 with age, gender or smoking history argues against such an explanation. One way to examine this possibility is through additional, larger, more closely matched studies. Another possible explanation is that any differences in NBEC from $\mathrm{BC}$ individuals compared to non-BC individuals resulted from development of $\mathrm{BC}$, instead of being a hereditary cause of increased risk for cancer. The best way to determine this will be to conduct a prospective study. In such a study, individuals matched for smoking history will be monitored for development of $\mathrm{BC}$ over time. The correlation of transcript abundance values for CEBPG relative to transcript abundance values for 
each of the antioxidant or DNA repair genes will be assessed. It is expected that the greatest incidence of BC will be among the heaviest smokers. Among the matched heaviest smokers, it is expected that CEBPG will be significantly correlated with each of the antioxidant or DNA repair genes among the non-BC individuals but not correlated in BC individuals.

Thus, there are multiple possible explanations for the observed findings. However, based on the preponderance of data thus far available, we conclude that CEBPG is responsible for optimal transcriptional regulation of key antioxidant or DNA repair genes in NBEC and that there is inter-individual variation in the regulation of each of these genes by CEBPG. If this conclusion is correct, the individuals at greatest risk for $\mathrm{BC}$ will be those with the most extreme smoking history combined with sub-optimal regulation of the largest number of antioxidant and DNA repair genes. This, in turn, leads to increased representation among BC individuals of individuals with lack of correlation between CEBPG and each of the affected antioxidant and/or DNA repair genes.

CEBPG is a truncated CEBP transcription factor [19] and possesses the sequences necessary for DNA binding and heterodimer formation, but lacks the sequences necessary for transactivation [20]. CEBPG forms heterodimers with other CEBP family members and in other tissues this leads to increased [21] or decreased [20] transcription of the regulated gene. CEBPG is known to have stimulatory effect on the IL- 6 and IL-8 promoters in B cell lines [21], and can also act as a dominant negative regulator of CEBPA and CEBPB in fibroblast and B cell lines [20].

The data from CEBPG knockout mice support a role for CEBPG in protecting lungs from oxidant damage. CEBPG1- knockout mice are healthy at birth but begin to die within 24 hours, and histological examination reveals emphysematous lungs [22]. In humans, risk for emphysema is associated with antioxidant capacity [23], and there is a strong correlation between risk for emphysema and risk for BC.

However, it will be important to obtain direct experimental evidence in NBECs for the role of CEBPG in regulating the antioxidant and DNA repair genes included in this study. Correlation between CEBPG and target gene transcript levels may not be associated with correlation at the protein level.

In this study, E2F1 correlation with DNA repair and antioxidant genes was less than the correlation observed with CEBPG, and the E2F1 correlation was observed in both non-BC individuals as well as $\mathrm{BC}$ individuals. The maintained correlation of E2F1 with DNA repair and antioxi- dant genes in $B C$ individuals suggests that this function is more tightly controlled in the population and does not play a role in determination of risk for BC. E2F1 has previously been reported to regulate transcription of DNA repair enzyme genes in other cell types, including primary human fibroblasts and mouse epidermal cells [24,25]. Clearly this would have survival value since DNA repair gene up-regulation in response to E2F1 provides additional DNA repair when the DNA is replicating and is particularly vulnerable to damage.

Epidemiologic assessment of the correlation between a particular variation in DNA sequence, or polymorphism, and risk for $\mathrm{BC}$ has been a dominant paradigm for many years. Thus far, these efforts have met with scant success [26]. A common limitation in design of such studies is that they involve assessment of a single polymorphism or occasionally, a few polymorphisms. Further, although the polymorphism assessed typically resides within a gene known to protect bronchial epithelium from carcinogens, oxidants, or DNA damage, the selection of the particular polymorphism for study is largely empiric, and not based on known functional properties. These are problems because multiple infrequent polymorphisms at different sites may all contribute to risk and unless the key polymorphisms can be identified through a functional test, a statistically valid assessment would require much larger study populations [27].

The findings of this study support a novel approach to identifying clinically useful biomarkers. According to the paradigm used in this study, a) a normal phenotype results from regulated transcription of a group of genes by one or more transcription factors, b) the corresponding risk-conferring or disease phenotype results from suboptimal interaction among those same genes, and c) each phenotype is identifiable and distinguishable through virtually-multiplexed transcript abundance analysis. The data presented here support the utility of this paradigm in identifying genes associated with risk for BC.

The next step will be to identify polymorphisms that affect regulation of XRCC1, ERCC5, GSTP1, SOD1, and GPX1 by CEBPG. Such polymorphisms should yield biomarkers suitable for more readily accessible samples, such as peripheral blood or buccal smears. A biomarker combining polymorphisms that affect regulation with those that affect function of antioxidant and DNA repair genes is likely to be the most accurate for identifying individuals at risk for BC. Biomarkers that accurately identify individuals at risk for BC will improve efficacy of chemoprevention and early detection clinical trials.

The observed inter-sample variation in the presence of gene-specific inhibitors of PCR provides evidence sup- 
porting the need for inclusion of an internal standard in each quantitative PCR transcript abundance measurement. Including such internal standards in the form of standardized mixtures of internal standards improves the reproducibility of transcript abundance measurement and enables development of a standardized database comprising virtually-multiplexed transcript abundance data. Virtually-multiplexed transcript abundance data are highly suited to identification of genes that have correlated transcript abundance values. Correlation at the transcript abundance level is an important property of genes that are co-regulated at the transcription level.

\section{Conclusion}

We conclude that in non-BC individuals, CEBPG regulates transcription of key antioxidant or DNA repair genes in NBEC and that in smokers who develop BC, CEBPG regulation is sub-optimal for a sufficient number of antioxidant and/or DNA repair genes to cause increased risk.

\section{Competing interests}

JCW and ELC each have significant equity interest in Gene Express, Inc., which produces and markets StaRT-PCR ${ }^{\text {TM }}$ reagents used in this study.

\section{Authors' contributions}

DNM participated in the design of the study, performed the TF identification, carried out TA measurements, coordinated and participated in the statistical analysis and drafted the manuscript. ELC contributed the preliminary data, participated in the design of the study and carried out TA measurements. SAK performed the statistical analysis for interpretation of data. DAH and YY consented patients and obtained the primary samples necessary for the study according to IRB regulations. JCW conceived of the study, participated in its design and coordination, and helped to draft the manuscript. All authors read and approved the final manuscript.

\section{Acknowledgements}

These studies and manuscript preparation were supported by grants from the National Cancer Institute (NCI), including CA85 I 47 and CA 95806, and the George Isaac Cancer Research Fund. StaRT-PCR reagents for measurement of some of the genes were provided at no cost by Gene Express, Inc. Neither the $\mathrm{NCl}$ nor Gene Express, Inc. had any role in study design, collection, analysis, or interpretation of data, writing of the manuscript, or in the decision to submit the manuscript for publication.

\section{References}

I. Weitberg AB: Cancer of the Lung: from molecular biology to treatment guidelines. Edited by: Weitberg AB. Totowa, Humana Press, Inc.; 2002.

2. Baldwin PD: Lung Cancer. Clinical Journal of Oncology Nursing 2003, 7(6):699-702.

3. Page GP, Green JL, Lackland D: Epidemiology of lung cancer with special reference to genetics, bioassays, women, and developing countries. Semin Respir Crit Care Med 2000, 2 I (5):365-374.

4. Anttila S, Hirvonen A, Vainio H, Husgafvel-Pursiainen K, Hayes JD, Ketterer B: Immunohistochemical localization of glutathione
S-transferases in human lung. Cancer Res 1993, 53(23):5643-5648.

5. Chu FF, Esworthy RS, Doroshow JH, Doan K, Liu XF: Expression of plasma glutathione peroxidase in human liver in addition to kidney, heart, lung, and breast in humans and rodents. Blood 1992, 79( I 2):3233-3238.

6. Ketterer B, Harris JM, Talaska G, Meyer DJ, Pemble SE, Taylor JB, Lang NP, Kadlubar FF: The human glutathione S-transferase supergene family, its polymorphism, and its effects on susceptibility to lung cancer. Environ Health Perspect 1992, 98:87-94.

7. Freeman BA, Crapo JD: Biology of disease: free radicals and tissue injury. Laboratory Investigation 1982, 47(5):4| 2-426.

8. Seeberg EELBM: The base excision repair pathway. Trends in Biochemical Sciences 1995, 20(10):391-397.

9. Crawford EL, Khuder SA, Durham SJ, Frampton M, Utell M, Thilly WG, Weaver DA, Ferencak WJ, Jennings CA, Hammersley JR, Olson DA, Willey JC: Normal bronchial epithelial cell expression of glutathione transferase $\mathrm{PI}$, glutathione transferase $\mathrm{M3}$, and glutathione peroxidase is low in subjects with bronchogenic carcinoma. Cancer Res 2000, 60:1609-1618.

10. Zhong $X$, Thornton K, Reed E: Computer based analyses of the 5 -flanking regions of selected genes involved in the nucleotide excision repair complex. International Journal of Oncology 2000, 17:375-380.

II. Crawford EL, Warner KA, Khuder SA, Zahorchak RJ, Willey JC: Multiplex standardized RT-PCR for expression analysis of many genes in small samples. Biochemical and Biophysical Research Communications 2002, 293:509-516.

12. Willey JC, Coy E, Brolly C, Utell MJ, Frampton MW, Hammersley JR, Thilly WG, Olson DA, Cairns K: Xenobiotic metabolism enzyme gene expression in human bronchial epithelial and alveolar macrophage cells. AmJRespCell MolBiol I996, I 4:262-27I.

13. Willey JC, Crawford EL, Knight CR, Warner KA, Motten CA, Herness EA, Zahorchak RJ, Graves TG: Gene expression profiling: methods and protocols-"Standardized RT-PCR and the Standardized Expression Measurement Center. In Methods in Molecular Biology 258th edition. Edited by: Shimkets RA. Totowa , Humana Press, Inc.; 2004.

14. Willey JC: Quality-controlled multi-gene expression measurement: an essential tool for the development of drugs and diagnostic tests. In PharmaGenomics Volume 2004. Edited by: Arzimanoglou I, Balough M, Bonn G, Cohen D, Dishman R, Finkelstein S, Foster C, Logan GW, Porcella A, Regnier FE, Royyuru A, Sinskey AJ, Speicher DW. Advanstar Communications; 2004:20-33.

15. Willey JC, Crawford EL, Knight CR, Warner KA, Motten CA, Herness EA, Zahorchak RJ, Graves TG: Standardized RT-PCR and the Standardized Expression Measurement Center. In Methods in Molecular Biology Volume 258. Issue 3 Edited by: Shimkets RA. Totowa, Humana Press, Inc; 2004:13-4I.

16. Workman J, Mark H: Comparison of Goodness of Fit Statistics for Linear Regression, Part I. Spectroscopy 2004, 19(4):38-4I.

17. GmbH GS: 2004 [http://genomatix.de/cgi-bin/eldorado/].

18. Quandt K, Frech K, Karas H, Wingender E, Werner T: Matlnd and Matlnspector: new fast and versatile tools for detection of consensus matches in nucleotide sequence data. Nucleic Acids Res 1995, 23(23):4878-4884

19. Johnson PF, Williams SC: . In Liver Gene Expression Edited by: Yaniv M, Tronche F. Austin, R.G. Landes Company; 1994:231-258.

20. Cooper C, Henderson A, Artandi S, Avitahl N, Calame K: Ig/EBP (C/ EBP gamma) is a transdominant negative inhibitor of C/EBP family transcriptional activators. Nucleic Acids Res 1995, 23(2I):437I-4377.

21. Gao H, Parkin S, Johnson PF, Schwartz RC: C/EBP gamma has a stimulatory role on the IL-6 and IL-8 promoters. I Biol Chem 2002, 277(4I):38827-38837.

22. Kaisho T, Tsutsui H, Tanaka T, Tsujimura T, Takeda K, Kawai T, Yoshida N, Nakanishi K, Akira S: Impairment of natural killer cytotoxic activity and interferon gamma production in CCAAT/enhancer binding protein gamma-deficient mice. J Exp Med 2005, I 90(I I): 1573-1582.

23. Repine JE, Bast A, Lankhorst I: Oxidative stress in chronic obstructive pulmonary disease. Oxidative Stress Study Group. AmJRespirCritCare Med 1997, 156:34I-357.

24. Ren B, Cam H, Takahashi Y, Volkert T, Terragni J, Young RA, Dynlacht BD: E2F integrates cell cycle progression with DNA 
repair, replication, and G(2)/M checkpoints. Genes Dev 2002, 16(2):245-256.

25. Berton TR, Mitchell DL, Guo R, Johnson DG: Regulation of epidermal apoptosis and DNA repair by E2FI in response to ultraviolet B radiation. Oncogene 2005, 24(I 5):2449-2460.

26. Caporaso NE: Why have we failed to find the low penetrance genetic constituents of common cancers? Cancer Epidemiol Biomarkers Prev 2002, I I ( I 2): I544- 1549.

27. $\mathrm{Xi}$, Jones IM, Mohrenweiser HW: Many amino acid substitution variants identified in DNA repair genes during human population screenings are predicted to impact protein function. Genomics 2004, 83(6):970-979.

\section{Pre-publication history}

The pre-publication history for this paper can be accessed here:

http://www.biomedcentral.com/1471-2407/5/141/pre pub

Publish with Bio Med Central and every scientist can read your work free of charge

"BioMed Central will be the most significant development for disseminating the results of biomedical research in our lifetime. "

Sir Paul Nurse, Cancer Research UK

Your research papers will be:

- available free of charge to the entire biomedical community

- peer reviewed and published immediately upon acceptance

- cited in PubMed and archived on PubMed Central

- yours - you keep the copyright

Submit your manuscript here:

http://www.biomedcentral.com/info/publishing_adv.asp
BioMedcentral 